SASBE

12,1

200

Received 31 January 2021

Revised 22 March 2021 6 April 2021

Accepted 6 April 2021

\section{Digital twin-based progress monitoring management model through reality capture to extended reality technologies (DRX)}

\author{
Sepehr Alizadehsalehi \\ Project Management Program, Department of Civil and Environmental Engineering, \\ Northwestern University, Evanston, Illinois, USA, and \\ Ibrahim Yitmen \\ Construction Engineering and Lighting Science, Jönköping University, \\ Jönköping, Sweden
}

\begin{abstract}
Purpose - The purpose of this research is to develop a generic framework of a digital twin (DT)-based automated construction progress monitoring through reality capture to extended reality (RC-to-XR).

Design/methodology/approach - IDEF0 data modeling method has been designed to establish an integration of reality capturing technologies by using BIM, DTs and XR for automated construction progress monitoring. Structural equation modeling (SEM) method has been used to test the proposed hypotheses and develop the skill model to examine the reliability, validity and contribution of the framework to understand the DRX model's effectiveness if implemented in real practice.

Findings - The research findings validate the positive impact and importance of utilizing technology integration in a logical framework such as DRX, which provides trustable, real-time, transparent and digital construction progress monitoring.

Practical implications - DRX system captures accurate, real-time and comprehensive data at construction stage, analyses data and information precisely and quickly, visualizes information and reports in a real scale environment, facilitates information flows and communication, learns from itself, historical data and accessible online data to predict future actions, provides semantic and digitalize construction information with analytical capabilities and optimizes decision-making process.

Originality/value - The research presents a framework of an automated construction progress monitoring system that integrates BIM, various reality capturing technologies, DT and XR technologies (VR, AR and MR), arraying the steps on how these technologies work collaboratively to create, capture, generate, analyze, manage and visualize construction progress data, information and reports.
\end{abstract}

Keywords Automated construction progress monitoring, Building information modeling, Reality capture, Digital twins, Extended reality

Paper type Research paper

\section{Introduction}

Based on Navon and Sacks (Navon and Sacks, 2007), the most cost-effective and efficient way to monitor construction projects' progress and measure their performance is to automate the process. So far, researchers have studied several emerging field data acquisition technologies to automate project inspections either by adopting a single technology or putting a combination of different technologies together (Alizadehsalehi and Yitmen, 2016; Asadi et al., 2021; Rasoolinejad et al., 2020). Some of these technologies/tools are laser scanners, image-based

(c) Sepehr Alizadehsalehi and Ibrahim Yitmen. Published by Emerald Publishing Limited. This article is published under the Creative Commons Attribution (CC BY 4.0) licence. Anyone may reproduce, distribute, translate and create derivative works of this article (for both commercial and non-commercial purposes), subject to full attribution to the original publication and authors. The full terms of this licence may be seen at http://creativecommons.org/licences/by/4.0/legalcode
Smart and Sustainable Built Environment Vol. 12 No. 1, 2023 pp. 200-236 Emerald Publishing Limited 2046-6099

DOI 10.1108/SASBE-01-2021-0016 
systems, radio frequency identification (RFID), wireless sensors (WSs), Global Positioning Systems (GPS), unmanned aerial vehicles (UAVs) and ultra-wideband (UWB). Among these technologies, numerous scholars adopted a 3D laser scan and nominated it as the most reliable available technology to capture 3D data for construction projects due to its speed and high precision (Perez-Perez et al., 2021). 3D laser scanning, $n-D$ BIM and object recognition framework (Scan-to-BIM) together offer a visually and detailed comprehensive assessment of the as-built state of construction projects within the project performance improvement context (Bosché et al., 2015).

Notwithstanding the significant impact of laser scanning data in the automation of construction progress monitoring, their applications are not rich, as they are limited to providing data solely by surface recognition. 3D point cloud data can only capture and measure the elements' surface, and they have lacks of reflecting the project's quality of built elements (Golparvar-Fard et al., 2019). Various researchers were adopting embedded sensing to assess conditional data of parts and elements of construction projects (Alizadehsalehi and Yitmen, 2016). Advancements in the generation of 3D geometric as-built data with laser scanner technologies and collecting various types of quality data regarding the project environment by using embedded advanced wireless sensors is an opportunity to explore projects comprehensively. Combining project as-planned models and as-built data from reality data capturing technologies to produce rich project data models can improve performance control and project management. Through this integration, decision-makers can find the chance to get access to data from laser scanners and installed sensors (as-built), besides the planned design, schedule and other required data in BIM space (as-planned).

On the other hand, gathering, saving, analyzing and managing these huge and complex data to get the simple, accurate, fast and real-time progress monitoring report needs a smart/ intelligent system that can continuously learn and updates itself from multiple sources such as historical archive data (Boje et al., 2020). The Io'T technologies and related systems act to collect real-time throughout the edge computing devices and the smart gateway. IoT enables access and connection to intelligence data and is interlinked with digital twin (DT) and digital models, which virtually represent their physical counterparts. As an umbrella term, cognitive computing consists of technologies, including big data, artificial intelligence (AI), machine learning (ML), deep learning (DL) and cognitive algorithms that try to simulate human thought processes in the computer model through DT technology. DT consists of physical and digital products, including connections between the two products (data that streams between them) (Dawood et al., 2020). Meanwhile, all data that created and captured digital data need to visualize on a real scale for all stakeholders in different stages of projects. Extended reality (XR) technologies can pull stakeholders in multidimensional directions with endless opportunities to create innovative and unique experiences of project status at any time (Alizadehsalehi et al., 2020).

In order to overcome current progress monitoring limitations, there is a need for a holistic framework for digital automated $n$-dimensional surface and quality progress monitoring based on available technologies. The main contribution to the knowledge domain is the insight into a DRX solution's functionality and its ability to visualize the comprehensive data included in a BIM system and generates real-time interactive project visualization that helps create a common understanding among significant stakeholders. Furthermore, the synthesization of industry professionals' questionnaire insights and comments further enables analysis of integrability enablers and professionals' perception of the technological ecosystem's usability. Knowledge of the interoperability potential between reality capturing data, BIM, DT, IoT and XR technologies could also contribute to the development of progress monitoring management practice. The result is improved communication regarding design, construction and operation and maintenance processes. The proposed study's main objective is to develop a framework of a DT-based reality capture to the extended reality (DRX) project progress management model through process modeling and IDEF0 language to provide a
To develop a generic framework of a 
SASBE

12,1

202

project central system, understand/validate the importance, strengths and challenges of the proposed system. This article also provides a roadmap for future efforts toward implementing a DRX-based management system in all construction industry stages in the automation of construction progress monitoring.

Figure 1 shows the structure of the article. The theoretical background about BIM-based construction progress monitoring, reality capturing technologies, DT and XR is provided. Then, the proposed DRX model for construction progress management using process modeling and IDEF0 modeling approach is presented. In the third stage, the research hypotheses and a quantitative method involving data collection and measures are explained using structural equation modeling (SEM) method, hypotheses are tested and the reliability of the factors is validated. Finally, the theoretical contributions and managerial implications are discussed, the proposed model's strengths and challenges and limitations presented and future research opportunities are suggested.

\section{Theoretical background}

This section outlines the key related works in four main areas relevant to this paper: (1) BIM-based construction progress monitoring; (2) reality capturing technologies (RC) in construction; (3) digital twins (DTs) and (4) extended reality (XR) in construction industry.

\subsection{BIM-based construction progress monitoring}

According to the Project Management Body of Knowledge (PMBOK), controlling and monitoring a construction project consists of those processes required to track, review and orchestrate the progress and performance of a project, identify any areas in which changes to the plan are required and initiate the corresponding changes (Guide, 2001). These processes involve the measurement of the progress through inspections (as-built) and the comparison with the project plan (as-planned) in order to validate the predicted performance. The overall purpose of monitoring is to ensure effectively managed results and outputs by measuring and assessing project performance (Lin and Golparvar-Fard, 2020). Measurement of work in progress on construction sites is vital for construction project management, and as this process directly affected different performances of a project such as time, cost, quality and safety of the project. It is considered one of the most challenging tasks due to the complexity and interdependency of activities (Arif and Khan, 2021).

Traditional progress tracking practice depends on visual inspections and daily or weekly reports created based on those inspections to ensure that work meets contract specifications and schedule (Golparvar-Fard et al., 2009). This traditional practice relies heavily on the inspectors' personal judgment, observational skills and expert weekly follow-up with a high probability of incomplete and inaccurate reports. However, if a project is poorly designed or based on faulty assumptions, even the best monitoring is unlikely to ensure its success. So, the AEC industry-accepted BIM, as a fast and accurate project progress tracking system, provides a suitable basis for automated construction progress monitoring.

Figure 1.

Research framework

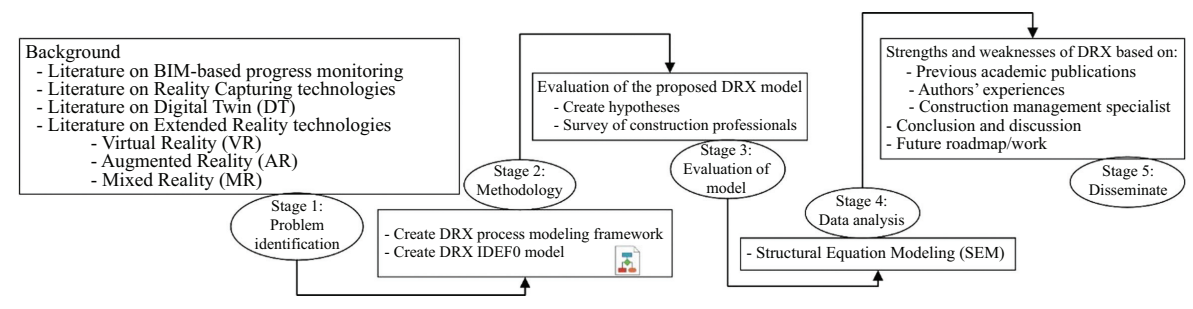


BIM is a comprehensive digital representation of a building comprising the 3D geometry of all its components and a semantic description of the component types and their relationships (Kim et al., 2020b). BIM is critically essential for progress monitoring in three different aspects: producing as-planned data, providing as-built data and comparing these two together (Machado and Vilela, 2020). As-planned data are construction progress-monitoring baseline. Nowadays, BIM can bind information associated with AEC contracts of a project as as-planned data repositories facilitate accessing geometrical data, visualizing designed schedule and information management about the progress. This is why BIM is accepted as a platform providing a rich and valuable data source for executing automated project progress monitoring (Kim et al., 2020a). A well-designed BIM model in the construction phase can analyze construction operations by enabling project managers to determine site management strategies, help to better communication and collaboration between project team members, facilitate contractor coordination and plan access routing and site logistics (Hamledari et al., 2021; Kopsida and Brilakis, 2020). BIM is considered a perfect launching platform for construction projects due to the capability for modeling existing building conditions.

\subsection{Reality capturing technologies for construction progress monitoring}

To generate as-built data, the construction field data capturing process requires various types of data (as required) from a construction project site (Braun et al., 2020). Data acquisition technologies are currently being widely used to capture the as-built information of exiting and ongoing construction projects. In the context of comparing as-planned data and as-built data, clash detection and visualizing discrepancies, BIM provides a very suitable, powerful and accurate baseline. In addition, BIM helps the communication and coordination of design and construction processes, real-time cost estimation and the automated creation of bills of quantity (Almukhtar et al., 2021; Elghaish et al., 2020).

So far, researchers have introduced numerous approaches and methods to create as-built BIM models for progress monitoring of construction projects (Nahangi and Haas, 2015). Most of them support a specific purpose of project control, such as physical status or the intended part's environmental condition. A laser scanner, UAV and digital camera are the most common reality capture technologies used to generate images, videos or 3D point cloud data (Rausch and Haas, 2021). Many research types considered laser-scanning systems a promising technology for as-built data acquisition due to their high precision (Czerniawski et al., 2021; Pica and Abanda, 2021). The laser scanning surveying technique's significant benefit is that it facilitates accurate, rapid and detailed 3D data of objects for use in numerous applications (Aryan et al., 2021). These models make it possible to access much of the necessary geometric and visual data. Airborne 3D scanners (UAV-Scanners) are unique because of their ability of the scanner to detach from the drone. Flexibility and various UAVbased scanners enable project stakeholders to utilize one scanner in the air and another on land. These laser technologies users can scan different scenarios, from large areas such as cities and railways, areas with no light such as tunnels and hard-to-document regions.

Wireless sensors (WSs) are low-cost, reliable and small devices able to perform a sensing task to monitor physical or environmental conditions. Typically, each WS node has the following different principal parts of (1) a radio transceiver, (2) microcontroller, (3) an electronic circuit for interfacing with the sensors and (4) an energy source such as a battery or any type of embedded form of energy harvesting. Sensor nodes differ in size and cost, based on the required data complexity. These specifications can affect the necessary resources, such as memory, computational speed, energy and communications bandwidth. WSs are equipped with one or more sensors, and they can collect data like temperature, humidity, sound, pressure, tension, lighting, gas level, vehicular movement monitoring, critical events detection, etc. (Rashid and Rehmani, 2016). These data can then be transmitted to the central
To develop a generic framework of a DT

203 
SASBE 12,1

receiver through a wireless medium. As shown in Table 1 , so far, considerable research and works have carried out different automated data capturing technologies, single or in integration with other data acquisition technologies, with or without BIM, toward data gathering.

\subsection{Digital twin in the built environment}

ADT is a digital replica of a living or nonliving physical entity, and it refers to a digital replica of potential and actual physical assets (physical twin), devices, systems, processes, places and people that can be used for different aims (Boje et al., 2020). This virtual twin exists only as software rendered by computing power (E1 Saddik, 2018). The DT concept started monitoring high-value, safety-critical pieces of machinery such as aircraft engines in flight and industrial processes. Generally, this system has three primary levels of the digital master, the digital shadow and the DT. The digital master is created parallel to product development and is based on the results of development. This level includes the virtual prototypes with their simulation and behavior models and the product's variants and configurations. With the beginning of an individual's life real instance of the product, the digital shadow arises. These real objects cast a digital shadow into the virtual world. Simply data such as identifiers and more complex data such as condition data, production data, maintenance data or usage data can be viewed. Depending on the DT's purpose, it is described which data must be taken into account to enable the intended functions. With the combination of the digital master information and digital shadow data, the result is the DT. Simulations and calculations can now be carried out based on the DT. Besides, automated service offerings based on the DT can also be generated to link products and services. DTs have various features such as realtime (gather and present real-time data of physical assets), analytics (store data, run continuous analytics from historical data and provide useful insight), simulations (utilize to run various data-driven simulations), visualization (overlay real-life and live 3D BIM models, images and videos of the physical asset and also foundation for immersive visualizations), automation (a bidirectional system that can manage the behavior of physical assets) and predictions (provide predictions of assets' future behaviors using historical data and analytics of various scenarios assets).

The concept of DT is gaining currency in the construction industry (Al-Sehrawy and Kumar, 2020). DT is an up-to-date and dynamic model of a physical asset or facility. It includes all the structured and unstructured information about projects that can be shared among team members. DTs help the AEC industry model, simulate, understand, predict and optimize all aspects of a physical asset or facility. Without DTs, most optimization is reactive based on after the fact alarms rather than predictive alerts. The design phase can create a solution virtually and accurately render it operational before a single physical action is taken (Deng et al., 2021). In this stage, a DT is used to create the optimum solution. It results from detailed simulations and rich data that specify the best architecture, configuration, materials and cost (Kan and Anumba, 2019). Then we can simulate that solution under different types of real scenarios. Based on the data provided, the design can then be modified. A DT can be used in the build phase to provide the construction specifications or parametric estimates to different providers (Shirowzhan et al., 2020). In this way, a DT can be an asset in streamlining the procurement process. Besides, and importantly, sensors are applied to the physical object to collect and transmit data back to its virtual replica during the build. At this point, with enough sensors, the virtual twin is providing all relevant data about the state of the physical twin. For example, an MEP section or structural element of a building can accurately render its temperature, vibration, strength and so much more in its DT. All of this becomes possible because of increasingly better digital technologies that include faster computers, better telemetry and communication of measurements from a collection point to receiving equipment, smaller, more accurate sensors, data management, and AI (Sacks et al., 2020). 


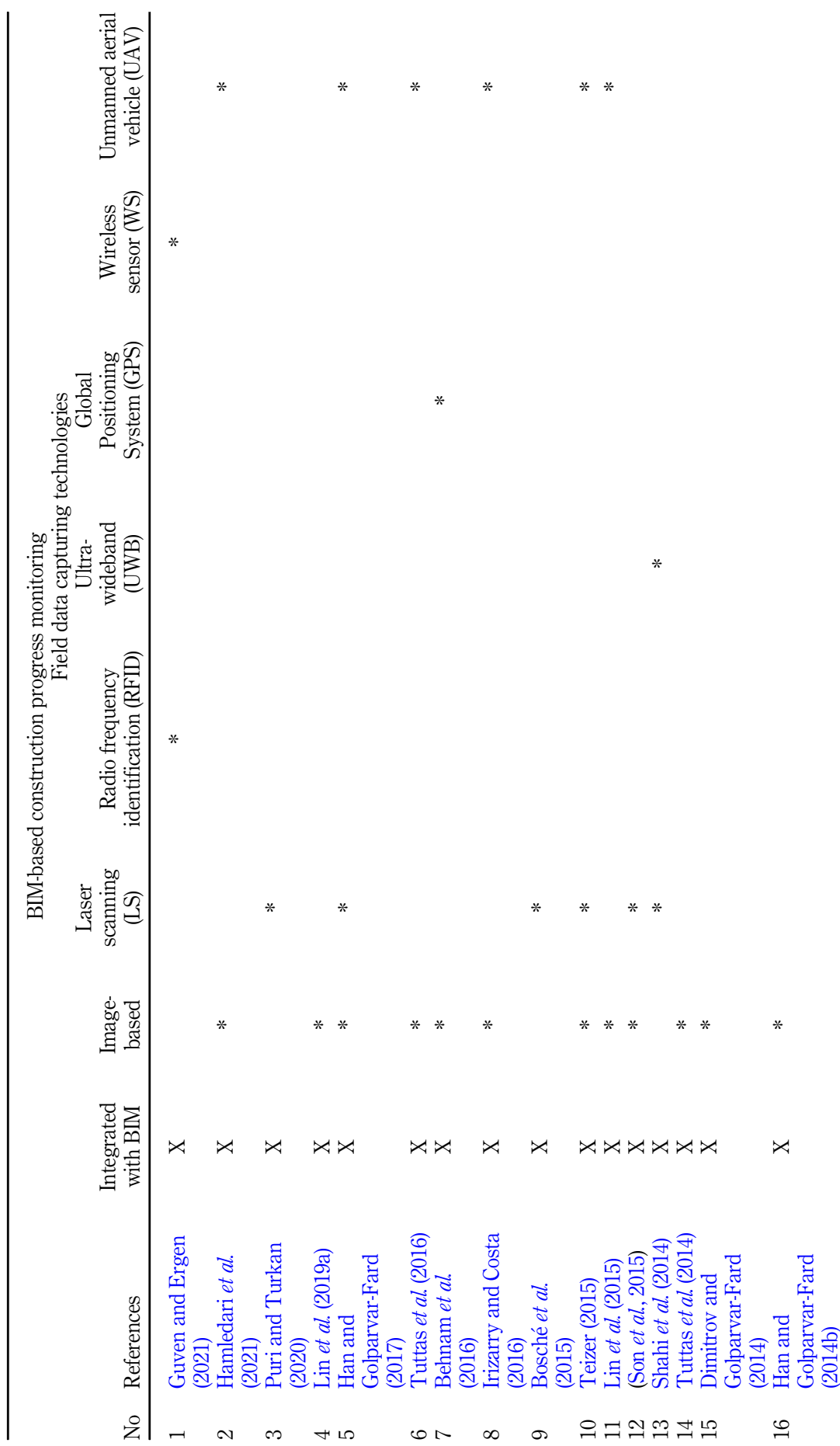

To develop a
generic
framework of a
DT

205

Table 1. Advanced reality capturing technologies for construction progress monitoring 
SASBE

12,1

206

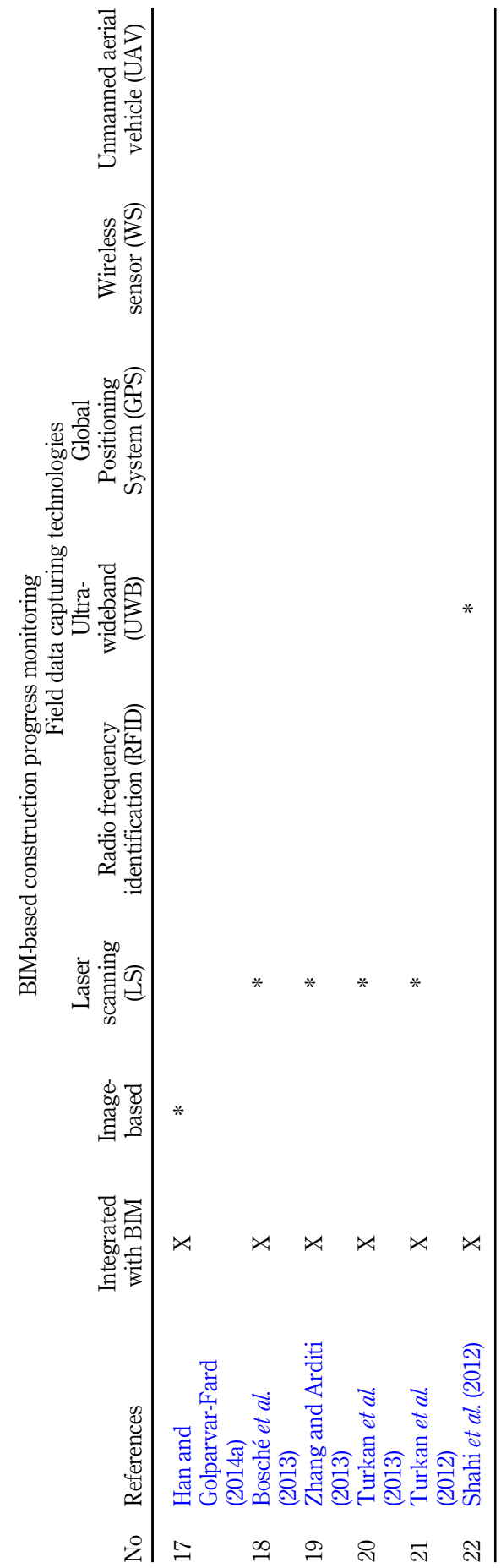

Table 1. 
An abundance of data is being collected and fed back to its DT over a digital thread during operations. Backed by AI, the DT can identify and even predict maintenance issues before they happen (Boje et al., 2020). It has become a data-informed model of a physical system. This compelling feature reduces cost since it is typically cheaper to conduct maintenance than repair it after facing issues proactively. Finally, this continuous real-time feed of data can help with optimization (Angjeliu et al., 2020). That is, improve its performance by enabling the system to automatically modify its behavior or prompt a human's manual intervention. DTs have become particularly ubiquitous in the IoT world. These Internet-connected electronics collect and produce data and services and interact and communicate with each other and central systems (Greif et al., 2020). The data collected from these devices create detailed knowledge, enabling capabilities. Diverse applications of DT, based on the latest research, have been shown in Table 2.

As stated, the DT concept offers numerous magnificent opportunities. However, various challenges need to be adequately addressed to achieve their full advantages. Providing realtime connectivity to assets that might constantly be moving or in remote areas is challenging. Besides, it required constant connectivity with significant bandwidth and computation power to gain value that is not a trivial issue.

A DT requires accurate and small different types of sensors. Managing and maintaining these sensors in different conditions is a challenging and complex process. All used technologies and platforms of DTs, in most cases, need to have long life cycles, and they need proprietary design, simulation or analytics software. This means that a cautious determination of the technologies to be used becomes a real fundamental success factor in the long run. In addition, DT's implementation needs a set of skills for which a set of personnel must be trained appropriately. DT gathers data and intellectual capital, which becomes more valuable over time; it is vital to ensure data management systems' security to avoid data loss or other possible damage. Finally, like other technologies, it needs firms and their stakeholders' culture changes to accept this massive digital transformation.

\begin{tabular}{|c|c|c|}
\hline No & References & Applications \\
\hline 1 & Deng et al. (2021) & Research on evolution of BIM to DTs in built environment applications \\
\hline 2 & Pan and Zhang (2021) & $\begin{array}{l}\text { build a data-driven DT framework based on BIM, IoT and data mining for } \\
\text { advanced project management }\end{array}$ \\
\hline 3 & $\begin{array}{l}\text { Bosch-Sijtsema et al. } \\
(2021)\end{array}$ & Applications of digital technologies in AEC industry \\
\hline 4 & Hasan et al. (2021) & $\begin{array}{l}\text { Investigating construction machinery operation and work tracking through } \\
\text { AR and DT }\end{array}$ \\
\hline 5 & Camposano et al. (2021) & Exploration on how AEC/FM practitioners describe DTs of built assets \\
\hline 6 & Hou et al. (2021) & Reviews the applications and challenges of DTs in construction safety \\
\hline 7 & Boje et al. (2020) & $\begin{array}{l}\text { Reviews the multi-faceted applications and limitations of BIM and need for } \\
\text { construction DT }\end{array}$ \\
\hline 8 & Liu et al. (2020) & Building indoor safety management \\
\hline 9 & Rausch et al. (2020) & Use of computational algorithm to support DTs in construction \\
\hline 10 & Dawood et al. (2020) & Review, develop and implement DT, VR, AR and BIM in AECO \\
\hline 11 & Götz et al. (2020) & Asset life cycle management \\
\hline 12 & Alonso et al. (2019) & SPHERE platform for improving the buildings energy performance \\
\hline 13 & Mathot et al. (2019) & $\begin{array}{l}\text { Developed and discussed the next generation parametric system Packhunt.io } \\
\text { with BIM, DT and mixed reality (XR) technologies }\end{array}$ \\
\hline 14 & Khajavi et al. (2019) & Discussed DT for building life cycle management \\
\hline 15 & Lu et al. (2019) & Proposed the DT-based smart asset management framework \\
\hline 16 & $\begin{array}{l}\text { Kaewunruen and Lian } \\
\text { (2019) }\end{array}$ & $\begin{array}{l}\text { DT for sustainability-based lifecycle management for railway turnout } \\
\text { systems }\end{array}$ \\
\hline
\end{tabular}

To develop a generic framework of a DT

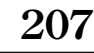

Table 2. Diverse applications of DT-based on the latest research in $\mathrm{AEC}$ industry 
SASBE

12,1

208

2.4 Visualization by extended reality $(X R)$

XR extends reality, and it means that it is still up for interpretation (Khairadeen Ali and Park, 2020). XR includes VR, AR, MR and similar reality-altering technologies that have been using immersive realities. VR is the classic immersive experience where we put on glasses and earphones and other devices to replace the real world with a virtual one in this completely simulated or virtual environment. The VR environments shut out the real world and everything, including the user (avatar), is virtual content. These models can be 360-degree photos or 360-degree video or $n$ - $D$ models. This is captured environments or situations that someone is standing in there and can experience that scenario or situation. VR tends to be interactive experiences, so this is the idea of interacting with objects or props or the environment itself. It is typically in an enclosed head-mounted display with surround audio (Khalili, 2021). AR is literally reality augmented with computer-generated content typically viewed through smartphones, tablets or glasses (Machado and Vilela, 2020). In AR, digital content is on top of the user's real world. The real world and whatever experience the AR device adds besides can be seen (Garbett et al., 2021). This data can be 3D stereoscopic or 2D, or a mix of the two. The idea of being in a real environment, but being able to receive information or real data as to what is happening in the real situation as it is happening. MR is very similar to $A R$, with higher interaction between virtual contents and the real world, making the user experience more realistic (Alizadehsalehi et al., 2019a). Not only do we see the computer-generated content mixed with reality but we can interact with that content, and that content can interact with the real world. This is where the interactive heads-up displays of science fiction fit. Users can feel virtual content with hands to scale what it is, and it feels like a user touching that content as seen in reality. Table 3 summarizes the latest research that used VR, AR and MR technologies, with or without BIM, for different AEC industry applications.

\section{Methodology}

This section presents a framework developed to improve automation in construction progress monitoring management referred to as the DRX model. The framework's processes and sub-processes are explained in detail and presented in process modeling and IDEF0 models. A comprehensive evaluation of the framework's DRX model is performed by conducting a questionnaire survey to 326 respondents and assessing their responses in light of similar experiences. All respondents were project managers, construction managers, VDC coordinators, $4 \mathrm{D}$ planners and BIM managers. Finally, the strengths and challenges of DRX drawn from the study are presented.

\subsection{Overview of proposed DRX model for construction progress management}

As demonstrated in Figure 2, this study aims to use reality capturing technologies with BIM as a powerful approach, real-time connectivity to DTs to analyze and optimize data, and visualize models on the XR environment on a real scale. Such a combination can be extended to a new generation of construction management performance monitoring. This combination includes using reality capturing technologies data, BIM, DTs and XR. Integration and utilization of these technologies in each under-construction project enable the stakeholders to collect real-time and precise actual data automatically, manage and optimize generated and captured data, visualize them and get the most comprehensive progress control. The input mechanisms or data sources in the DRX model are divided into two levels: creating an asplanned model and acquiring an as-built model. In creating the as-planned stage, the project design team, including the architect team, structural engineer team, the MEP team and the administration team, must identify information that should be included in BIM models, which 


\begin{tabular}{|c|c|c|c|c|c|c|c|}
\hline No & References & VR & $\mathrm{AR}$ & MR & $\begin{array}{l}\text { Integated } \\
\text { with BIM }\end{array}$ & Applications & $\begin{array}{l}\text { To develop a } \\
\text { generic }\end{array}$ \\
\hline 1 & Dai et al. (2021) & & & $*$ & $\mathrm{X}$ & $\begin{array}{l}\text { Increasing safety communication on } \\
\text { construction sites }\end{array}$ & DT \\
\hline 2 & Hasan et al. (2021) & & $*$ & & $\mathrm{X}$ & $\begin{array}{l}\text { Investigating construction machinery } \\
\text { operation and work tracking through AR } \\
\text { and DT }\end{array}$ & 209 \\
\hline 3 & $\begin{array}{l}\text { Bosch-Sijtsema et al. } \\
\text { (2021) }\end{array}$ & $*$ & $*$ & $*$ & $\mathrm{X}$ & $\begin{array}{l}\text { Applications of digital technologies in } \mathrm{AEC} \\
\text { industry }\end{array}$ & \\
\hline 4 & Piroozfar et al. (2021) & & $*$ & & $\mathrm{X}$ & $\begin{array}{l}\text { Study on the application of AR technologies } \\
\text { for urban utility infrastructure }\end{array}$ & \\
\hline 5 & $\begin{array}{l}\text { Alizadehsalehi et al. } \\
(2020)\end{array}$ & $*$ & $*$ & $*$ & $\mathrm{X}$ & $\begin{array}{l}\text { Review of XR technologies in AEC industry } \\
\text { and presented an implementation workflow } \\
\text { within a NASA-Mars habitat case study }\end{array}$ & \\
\hline 6 & Wu et al. (2020) & $*$ & $*$ & $*$ & $\mathrm{X}$ & $\begin{array}{l}\text { Review and proposed various applications } \\
\text { of BIM-XR }\end{array}$ & \\
\hline 7 & Cheng et al. (2020) & & & * & $\mathrm{X}$ & Applications in the AECO Industry & \\
\hline 8 & $\begin{array}{l}\text { Wen and Gheisari } \\
(2020)\end{array}$ & * & & & $\mathrm{X}$ & $\begin{array}{l}\text { Facilitate communication in the AEC } \\
\text { domain }\end{array}$ & \\
\hline 9 & $\begin{array}{l}\text { Rahimian et al. } \\
(2020)\end{array}$ & $*$ & & & $\mathrm{X}$ & Monitoring of construction projects & \\
\hline 10 & Cheng et al. (2020) & & & * & $\mathrm{X}$ & Applications of MR in the AECO Industry & \\
\hline 12 & $\begin{array}{l}\text { Alizadehsalehi et al. } \\
\text { (2019a) }\end{array}$ & & & $*$ & $\mathrm{X}$ & $\begin{array}{l}\text { Integration of BIM, lean construction and } \\
\text { MR }\end{array}$ & \\
\hline 13 & $\begin{array}{l}\text { Davidson et al. } \\
\text { (2019) }\end{array}$ & * & & & $\mathrm{X}$ & $\begin{array}{l}\text { To facilitate real-time creation of bill of } \\
\text { quantities during the design phase }\end{array}$ & \\
\hline 14 & $\begin{array}{l}\text { Alizadehsalehi et al. } \\
\text { (2019b) }\end{array}$ & * & & & $\mathrm{X}$ & Design and construction education & \\
\hline 15 & $\begin{array}{l}\text { Potseluyko and } \\
\text { Rahimian (2019) }\end{array}$ & $*$ & $*$ & & $\mathrm{X}$ & $\begin{array}{l}\text { Improving business and technical } \\
\text { operations within timber frame self-build } \\
\text { housing sector }\end{array}$ & \\
\hline 16 & Du et al. (2018) & * & & & $\mathrm{X}$ & Collaborative decision-making & \\
\hline 17 & Shi et al. (2018) & * & & & & Construction safety & \\
\hline 18 & Mo et al. (2018) & * & & & $\mathrm{X}$ & Construction safety training & \\
\hline 19 & $\begin{array}{l}\text { Chalhoub and Ayer } \\
\text { (2018) }\end{array}$ & & & $*$ & $\mathrm{X}$ & Prefabrication & \\
\hline 20 & $\begin{array}{l}\text { Olorunfemi et al. } \\
\text { (2018) }\end{array}$ & & & $*$ & & Construction safety communication & \\
\hline 21 & $\begin{array}{l}\text { Chalhoub et al. } \\
\text { (2018) }\end{array}$ & & & $*$ & $\mathrm{X}$ & Site survey & \\
\hline 22 & Chu et al. (2018) & & * & & $\mathrm{X}$ & Evaluate the effectiveness of BIM and AR & \\
\hline 23 & Hou et al. (2017) & $*$ & $*$ & & & $\begin{array}{l}\text { Operation, maintenance, productivity and } \\
\text { safety }\end{array}$ & \\
\hline 24 & Du et al. (2017) & * & & & $\mathrm{X}$ & Collaborative decision-making & \\
\hline 25 & Azhar (2017) & * & & & $\mathrm{X}$ & Construction safety & \\
\hline 26 & $\begin{array}{l}\text { Klempous et al. } \\
(2017)\end{array}$ & $*$ & & & $\mathrm{X}$ & Construction safety & \\
\hline 27 & Paes et al. (2017) & $*$ & & & & $\begin{array}{l}\text { Improving the understanding of } \\
\text { architectural 3D models }\end{array}$ & \\
\hline 28 & Haggard (2017) & $*$ & & & $\mathrm{X}$ & $\begin{array}{l}\text { Benefits and challenges for VR in } \\
\text { construction industry }\end{array}$ & \\
\hline \multicolumn{7}{|c|}{$\begin{array}{l}\text { Note(s): } \mathrm{VR}=\text { Virtual Reality; } \mathrm{AR}=\text { Augmented Reality } ; \mathrm{MR}=\text { Mixed Reality } R=\text { Review; } F=\text { Framework; } \\
S=\text { Survey; CS = Case Study; } I=\text { Interview }\end{array}$} & $\begin{array}{r}\text { XR technologies in } \\
\text { AEC industry }\end{array}$ \\
\hline
\end{tabular}


SASBE

12,1

210

Figure 2.

Overall approach of DRX

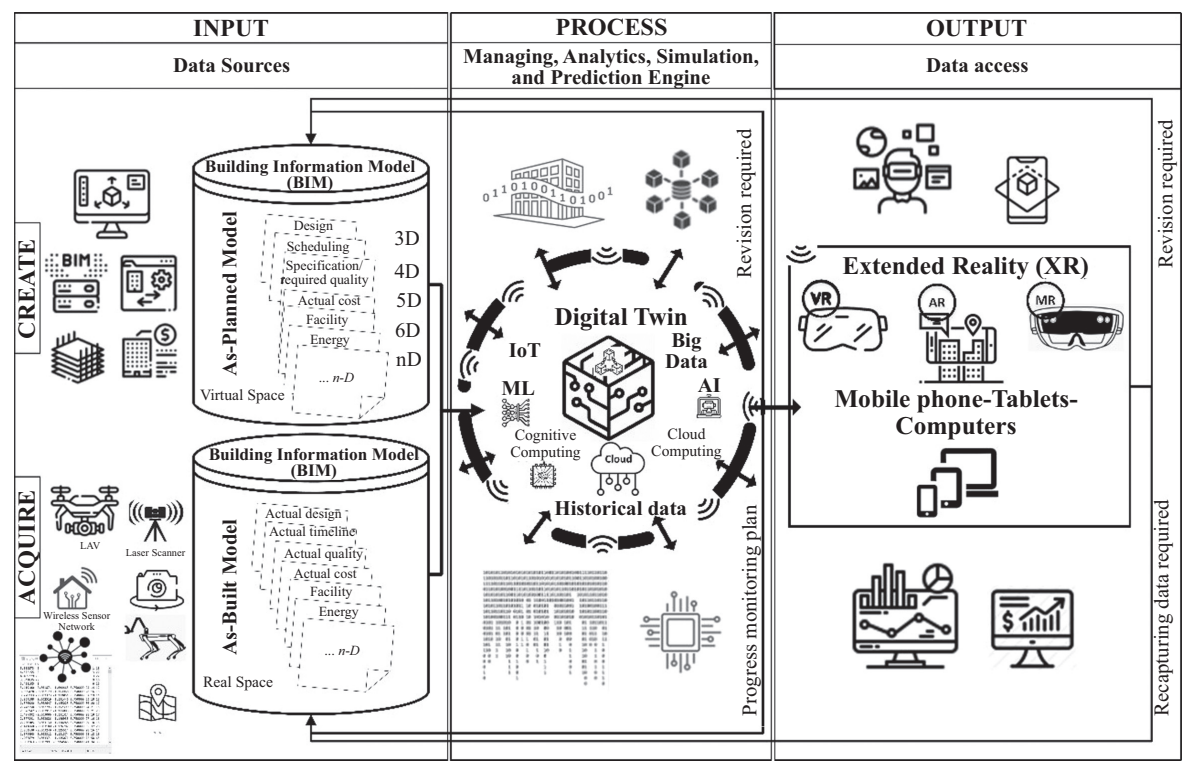

multiple layers can represent. During the pre-construction phase, BIM has the potential to retain the connections between designs, models, scheduling, cost and other items activities so that any design or resource change can be reflected in the estimate, schedule, etc. The acquiring as-built model is capturing/collecting data, but various types of reality capturing technologies such as laser scanner, digital cameras, UAVs and wireless sensors. These created and captured data can be input in different exchange formats such as RVT, TXT, DWG, XYZ, E57, etc.

These various created and captured data (big data) integrate into a common data environment (CDE) in a BIM-based DT engine to be managed, analyzed and simulate in the process stage. In the process stage of DRX, DT, with the help of AI, IoT, machine learning and cognitive computing based on the project execution plan, defined level of development (LOD), created information and historical archive data, a progress monitoring plan was created to show all critical places to monitor, exact timeline and required report. Various available APIs can be used in this stage to customize the DT.

The final stage of the DRX model is the output or data access. In this stage, XR technologies help responsible teams visualize the model in a real scale environment before construction started to see all possible progress monitoring scenarios to choose the best one in terms of safety, quality, speed, price and ease. The results of a progress comparison study between as-planned data and as-built data performances are ultimately visualized in the BIM environment and create different real-time progress reports. These comparison data can be seen on a real scale environment by XR devices or regular smartphones, computers or tablets.

\subsection{IDEFO for DRX construction progress management (AO)}

The development of a management system for any practical purpose should be based on understanding the process details. IDEF0 is one of the methodologies that can describe manufacturing functions and the one that can provide a mechanism for the communication of complex concepts through the simple use of boxes and arrows (Waissi et al., 2015). IDEF0 is an acronym for ICAM definition for function modeling, where ICAM stands for integrated 
computer-aided manufacturing. In this study, an IDEF0 data modeling method has been designed to establish an integration of reality capturing technologies using BIM, DTs and XR for automated construction progress monitoring. This model implemented in this research, as shown in Figure 3, is composed of five major processes: generate a digital as-planned model (node A01), generate a digital as-built model (node A02), data management process (node generic framework of a A03), visualization (node A04) and analysis progress monitoring (node A05).

(1) Creating digital as-planned model based on goals, budget, specifications, LOD and standards, BIM knowledge and DT mechanisms (A01).

(2) Generating digital as-built model with sensors, laser scanners and cameras (A02). There are as-planned and as-built data and data that need to be registered, combined and managed.

(3) Data management which use DT, CC and software analytics (A03).

(4) Visualization stage that use XR technologies (A04).

(5) Analyzing progress monitoring to see the deviations between as-built and as-planned models and optimizing our decision-making processes (A05).

This model focuses on the design and built stages of a project called pre-construction and construction stages. The top level of the IDEF0 model consists of one single box (A0), which illustrates the whole DRX construction progress management process. The primary outputs are a more comprehensive, precise and real-time progress visualization and reports ready for use by the client, inspectors and other related stakeholders of projects to see the status of a project and find easily understand the deviation between as-built and as-planned remotely from out of job site or at the job site to make the best decisions.

The DRX process is based on massive, cumulative, real-time, real-world BIM and field measurements data. As highlighted in the DRX IDEF0 model, one of the primary stages is defining the level of detail and complexity of a results representation that refers to LOD. This LOD is defining all goals, requirements and objectives of the project. The LOD can be changed as the model moves away from the viewer or other metrics such as object importance, viewpoint-relative speed or situation.

These processes are presented in Table 4 as a node index, a listing showing all nodes in an IDEF0 model in the outline order. Each of the five processes and their sub-processes is explained in the following sections.

\subsection{Digital as-planned BIM model (AO1)}

On the second level of the DRX model (A01), a more comprehensive view of the progress monitoring management process is described using four different activities as shown in Figure 4. In the activity, digital as-planned model (A01), the process of generating a digital as-planned BIM model is defined. This activity is composed of seven (7) major processes: create a design model (A011); real-time visualization (A012); creating a schedule (A013); creating cost estimation (A014); optimizing the created BIM model by DTs mechanisms (A015); identifying monitoring goals (A016) and creating a plan for progress monitoring in the construction stage (A017).

(1) Creating a design model and visualization is a kind of loop that helps designers draw, visualize, check the design through XR technologies and get a high-quality design (A011 and A012).

(2) After drawing a high-quality plan, add a timeline and cost of the project (A013 and A014). 
SASBE

12,1

\section{2}

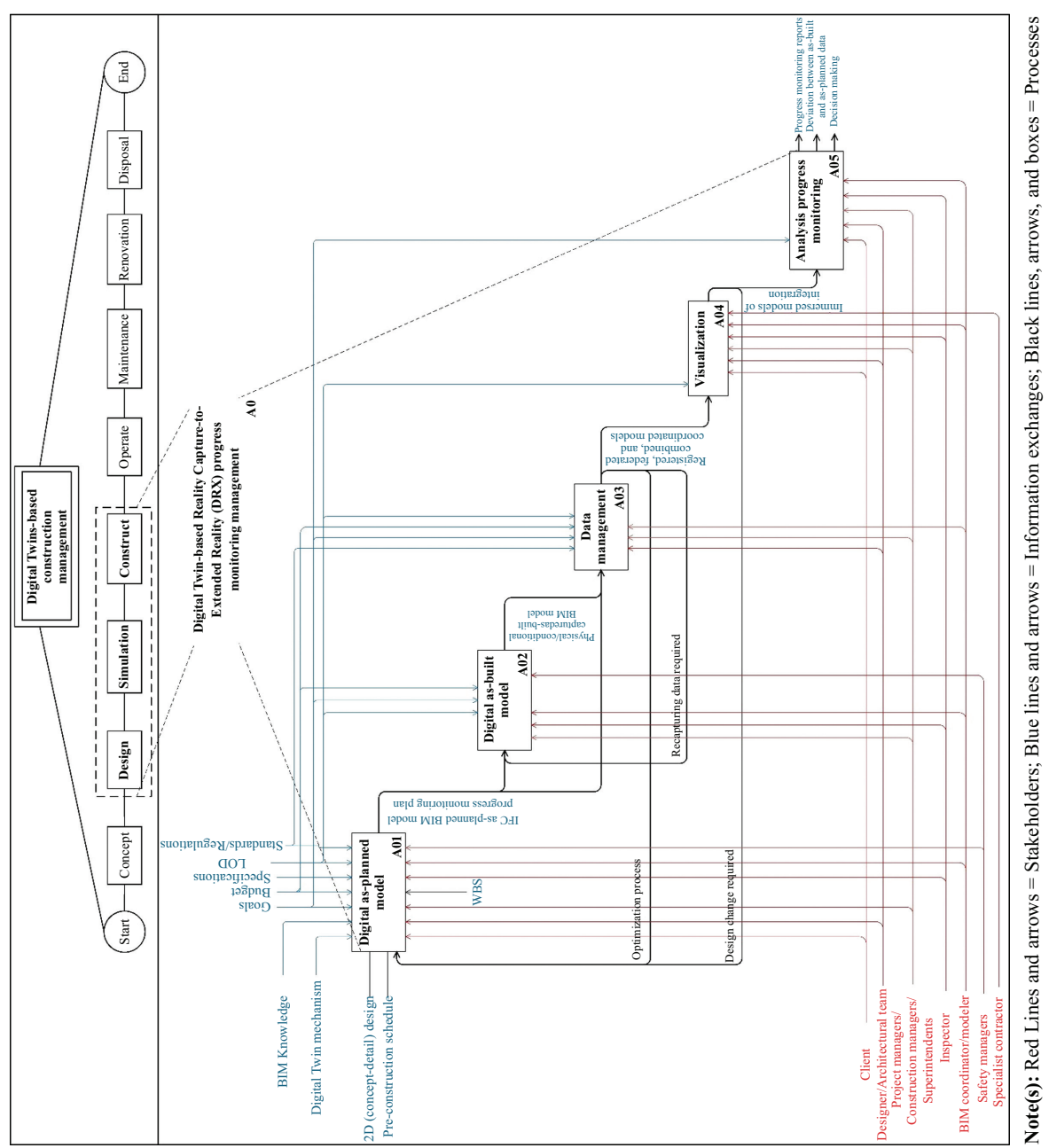

Figure 3.

IDEF-0 representation of DRX Model 


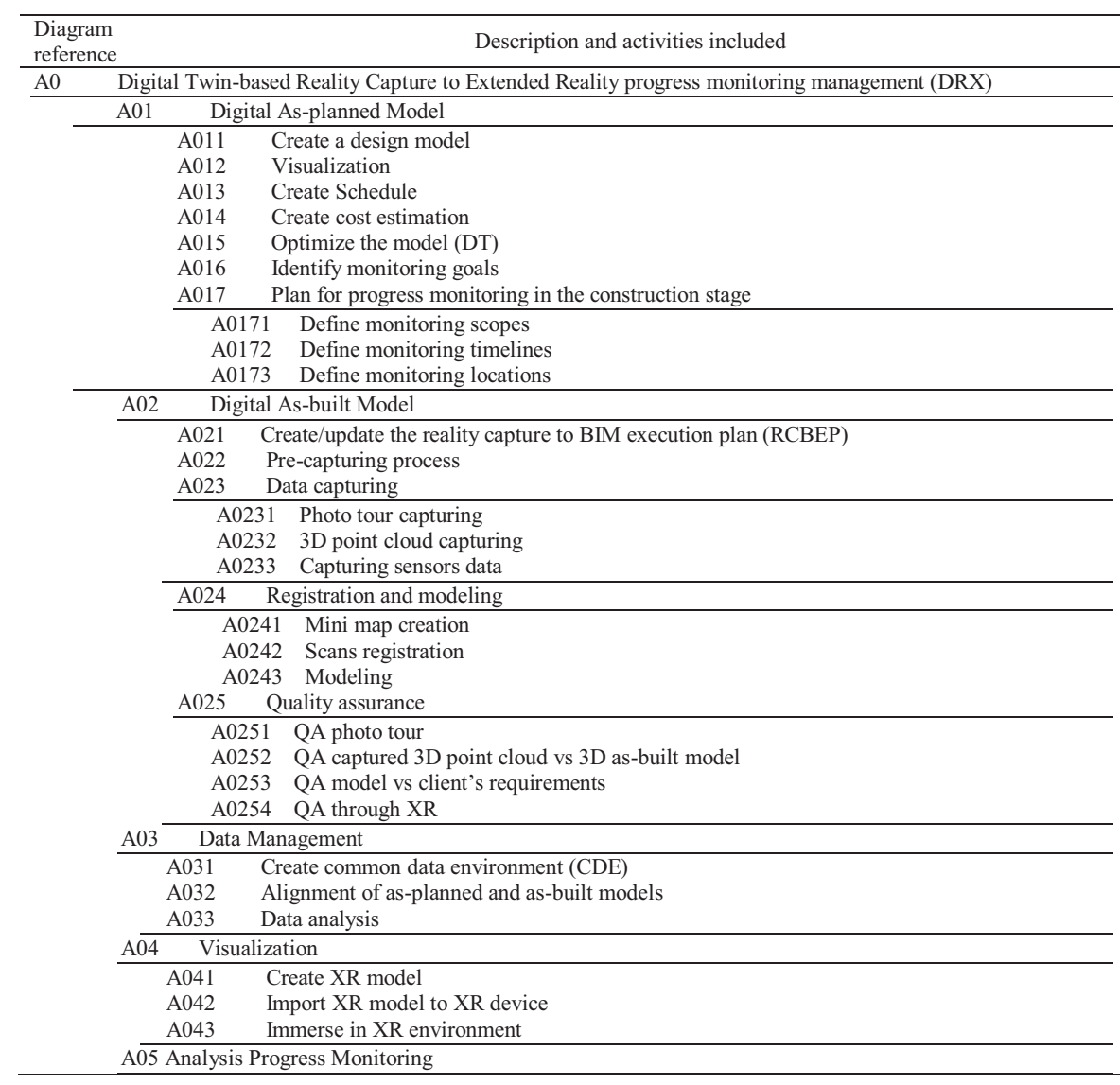

Optimize the model (DT)

Identify monitoring goals

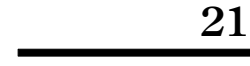

Table 4.

Node index for DRX framework

(3) Using DT to optimize the model (A015).

(4) At this stage, an optimized plan is ready to identify the monitoring goals and then create the progress monitoring plan. It is known what is critical for the project, so the responsible teams define a progress monitoring plan based on scopes, timeline, and locations. Then, the required sensors are put, drones are sent, scanners or cameras are used to capture progress monitoring data (A016 and A017).

The main outputs are generated final and optimized digital as-planned model and a detailed progress monitoring plant to use at the construction stage by various stakeholders such as inspectors, project managers and superintendents. In this framework, stakeholders can visualize the model on a real scale and identify their future progress monitoring goals based on the project's critical points. Defining the pre-construction stage's monitoring goals helps architects, the BIM team and other responsible stakeholders create a comprehensive and accurate progress-monitoring plan from the pre-construction stage. The DRX model needs to identify and know the progress monitoring objectives. For instance, what parts, elements and attribution of components need to be monitored, what accuracy and level of details are 
SASBE

12,1

214

Figure 4.

IDEF-0 representation of DRX Model

(Generating Asplanned model)

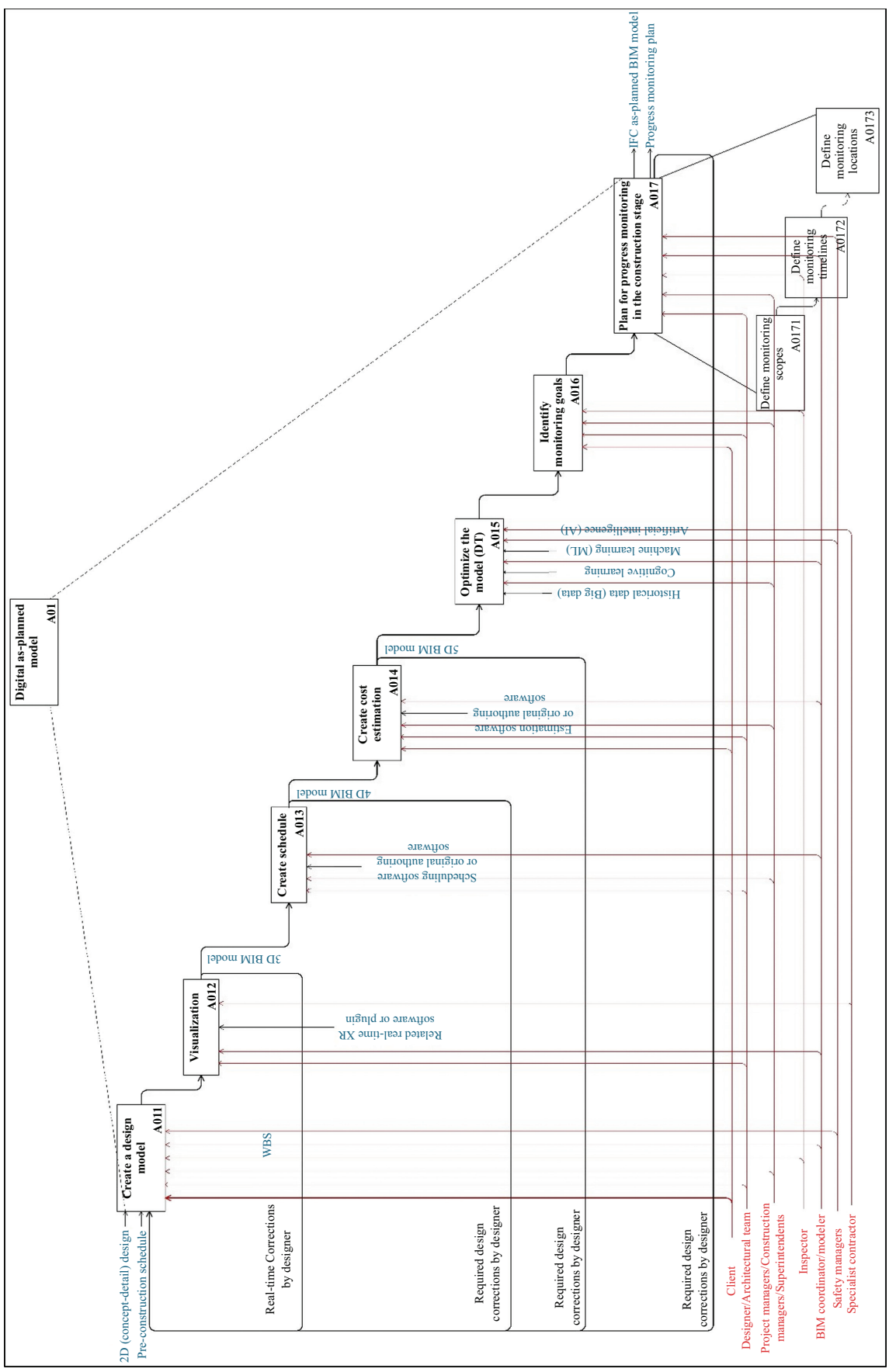


required for each element and which view must be inspected. The determination of monitoring objectives is the primary act toward the determination of proper monitoring techniques and technologies.

\subsection{Create progress as-built model (AO2)}

The second phase (A02), as seen in Figure 5, is the generating of the as-built model, and the activities in this section are: create/update the RCBEP document (A021); pre-capturing process (A022); data capturing (A022); registration and modeling (A024); and quality assurance (A025).

(1) A Reality Capture to BIM Execution plan (RCBEP) is created based on as-planned model and progress monitoring plan from the previous section and information from job site (A021).

(2) The pre-capturing process is needed to go through RCBEP to conduct review project objectives and create a capturing plan, including all logistics. (A022).

(3) Data capturing from the job site contains capturing photo 360 s, point clouds and gathering sensors data (A023).

(4) Registration, combining and generating a single file included all data together and, if required, convert to a 3D BIM model (A024).

(5) The generated file is needed to go through quality assurance to ensure that the captured and registered file is correct (A025).

\subsection{Data management (AO3)}

As shown in Figure 6, the activities included in the data management stage (A03) are Create Common Data Environment (CDE) (A031); Alignment of As-planned and As-built (A032) and Data analysis (A033). In the next step, by different software and application and also available programming interfaces (APIs), the as-built and as-planned data can be aligned and coordinated in a single scale, format, and a shared CDE (A031) and (A032). The system then uses $\mathrm{AI}, \mathrm{ML}$ and cognitive computing to choose the correct information to manage and analyze this massive amount of information and data (A033). An intelligent construction progress monitoring system can provide any amount of data or information in real-time to the project stakeholders. With DT, all stakeholders are able to harness, analyze, interpret and give them unique, actionable insights for those that manage, operate and experience buildings and infrastructure projects. These sections optimize created and generated data to enhance the project performance by having all these data and knowledge connected.

As the broad majority of target systems have multiple variables and multiple data streams, the DT requires cognitive computing, AI and ML. Therefore, the system at this stage is able to do various cloud analyses, such as clash detection. The system is also able to analyze the available historical data from previous projects to help stakeholders make quick, accurate decisions. In the end, data can export in various formats required to use by the stakeholders, which have been mentioned in the RCBEP document mentioned in section (A021). DT technology is one of the essential Industry 4.0 technologies currently started and improving every day.

\subsection{Visualization (A04)}

Visualization involves as-planned and as-built data to monitor data at the real scale in various $\mathrm{VR}, \mathrm{AR}$ and MR environments. Various available hardware, software and plugin (APIs) help stakeholders to visualize models. The BIM-to-XR development framework encompasses
To develop a generic framework of a DT 
SASBE

12,1

216

Figure 5.

IDEF-0 representation of DRX Model

(Generating Asbuilt model)

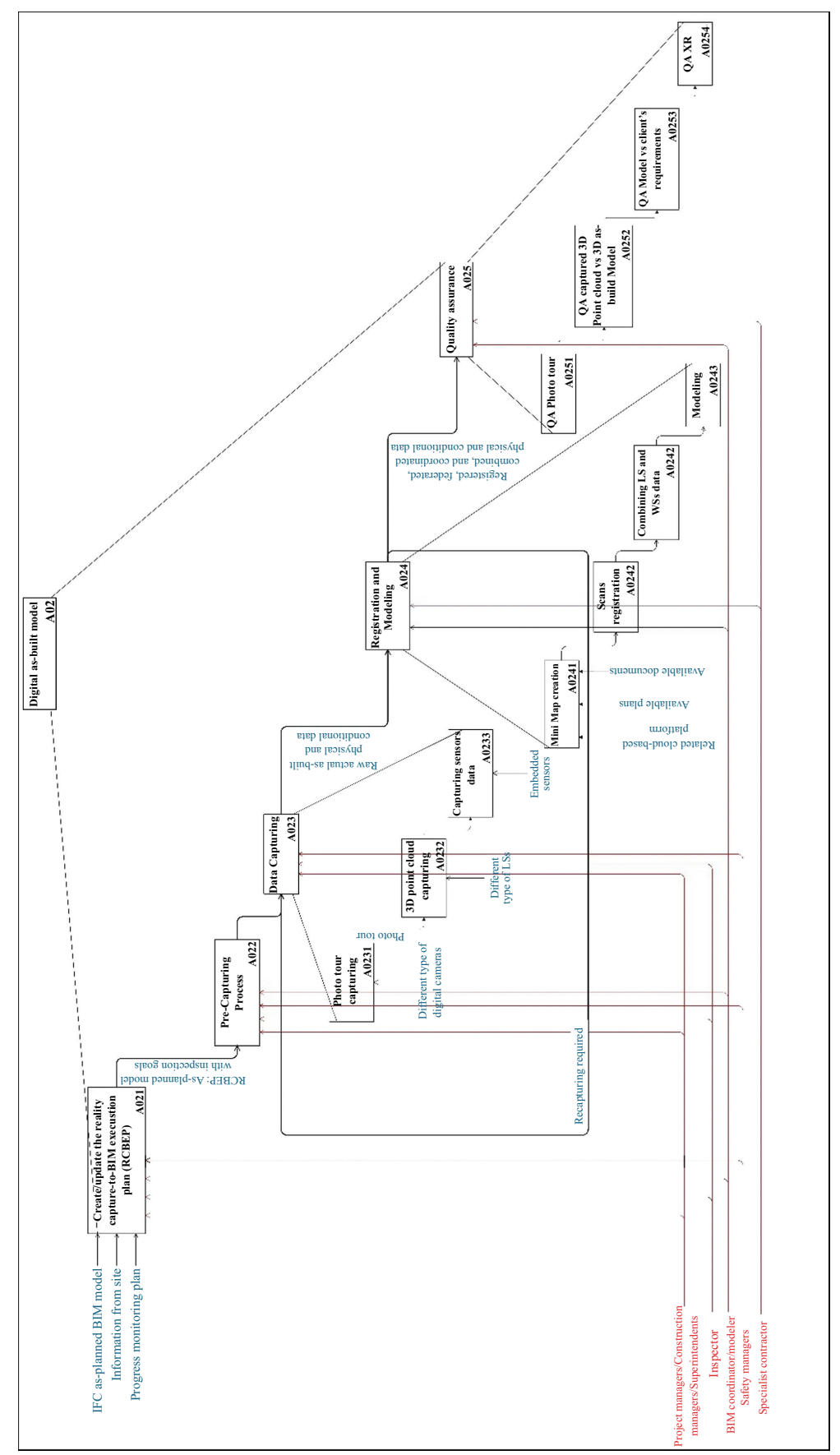


three main activities: create an XR model (A041); import an XR model to an XR device (A042) and immerse users in an XR environment (A043). As shown in Figure 7, an XR model is determined according to specifications, BIM knowledge and ideas from designers and stakeholders (node A03). At this stage, the model is ready to use by different types of XR devices and applications (node A04). The created XR model can then be used to analyze the

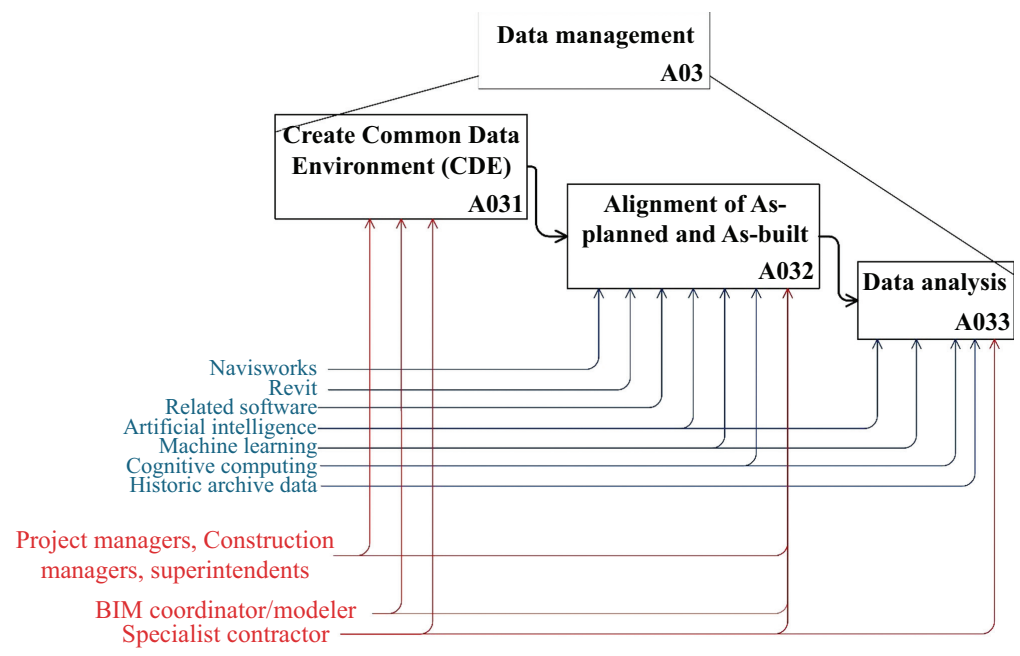

Note(s): Red Lines and arrows $=$ Stakeholders; Blue lines and arrows $=$ Information exchanges; Black lines, arrows, and boxes $=$ Processes

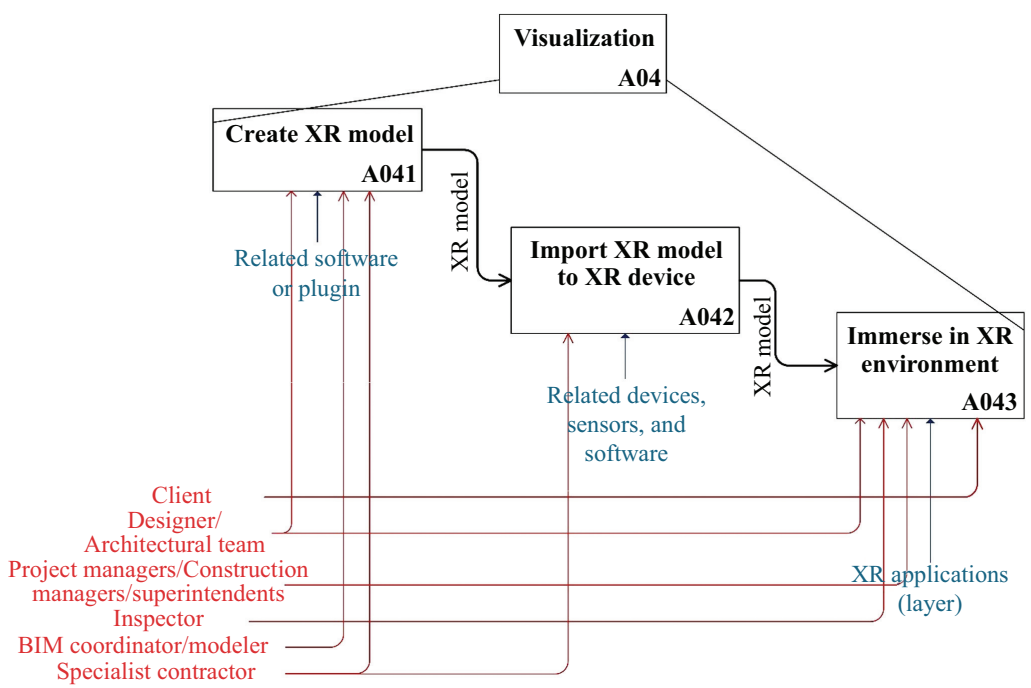

Note(s): Red Lines and arrows $=$ Stakeholders; Blue lines and arrows $=$ Information exchanges; Black lines, arrows, and boxes $=$ Processes
To develop a generic framework of a DT

Figure 6.

Data management process at the as-built generation stage
Figure 7.

Visualization of asplanned and as-built data to monitor data at XR environments 
SASBE 12,1

\section{8}

overall design and evaluate alternative design decisions to take corrective actions on design and make better design decisions (node A05), as seen in Figure 7.

\section{Evaluation of the proposed model}

The developed system DRX integrates all the proposed technologies currently existing, but is on their path of evolution. The real applications for each of these emerging technologies have been described one by one. However, as technologies such as DT is not fully adapted to be used specifically for the construction process in the AEC industry, as the last part of the research, the reliability, validity and contribution of the proposed framework to understand the effectiveness of the DRX model when implemented in real practice.

\subsection{Research hypotheses}

Figure 8 displays the correlations among the four major aspects in the DRX model, based on the extensive literature review and the detailed IDEF0 diagram: AEC digital technologies, 4D building information modeling (BIM), digital twins and automated project progress monitoring.

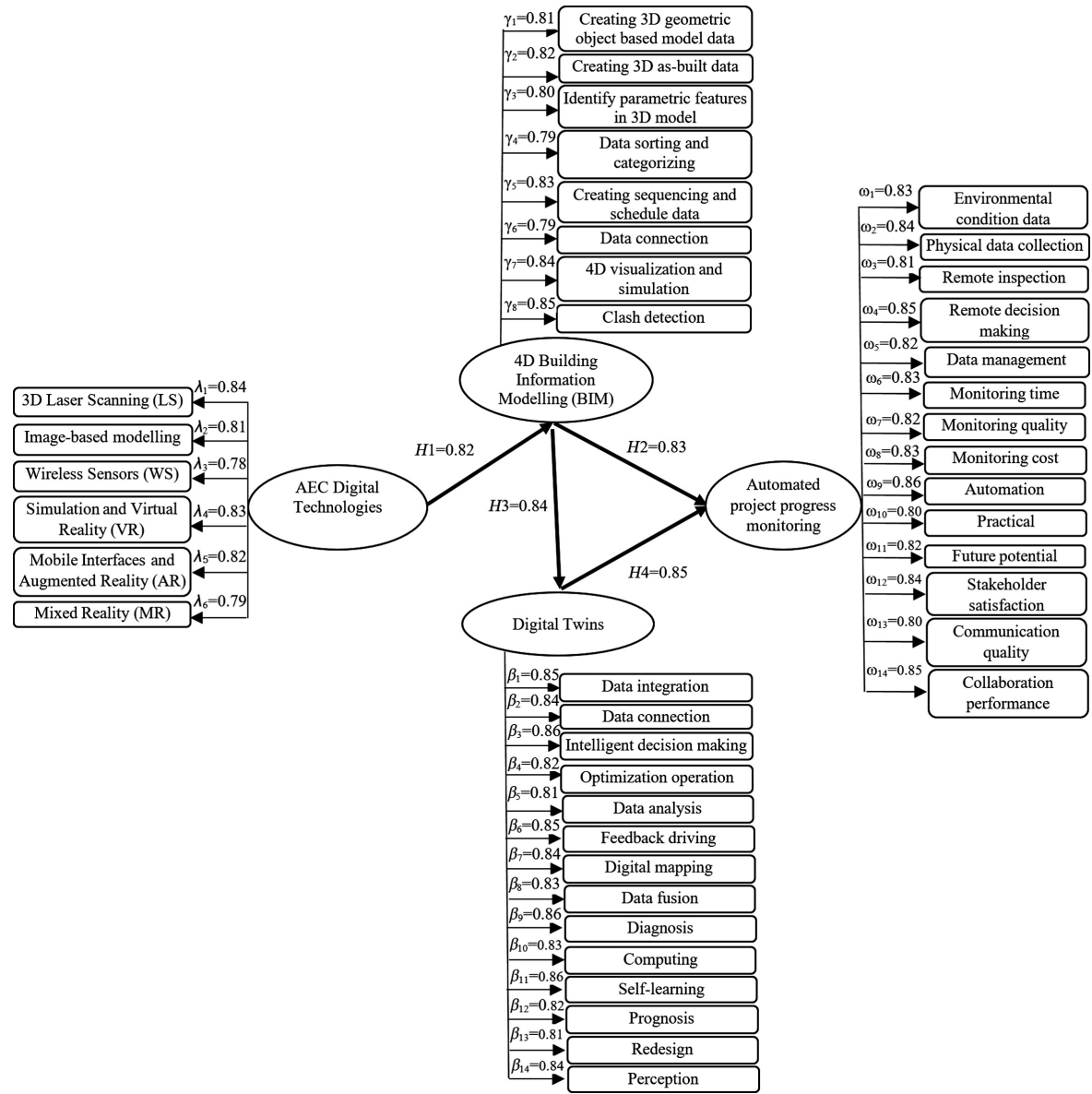

Figure 8.

Hypothesized SEM model 
The subsequent four hypotheses aim to explain the relationship among the construct measures and the other variables and the theoretical background to these relationships.

H1. Leveraging of AEC digital technologies facilitates generation and simulation of 4D BIM model.

H2. Utilizing 4D BIM simulations enhance automated project progress monitoring.

H3. Facilitating 4D BIM models constitute the generation of digital twins.

H4. The digital twins enrich the simulated data and empower automated project progress monitoring performance.

\subsection{Sampling and data collection}

Using a computerized self-administered questionnaire (CSAQ), questionnaires with the designed IDEF0 model were sent to the project management professionals such as BIM managers, 4D planners, VDC coordinators, construction managers and project managers in the consulting and contracting firms. The sample covers only large firms, constructing a typical project with a value greater than $5 \mathrm{~m}$ USD, carrying out $10-25$ projects per year or having more than 100-200 employees, whereas an engineering consulting company is designing and controlling a typical project with a value greater than $5 \mathrm{~m}$ USD, carrying out 25-50 projects per year or having more than 25-50 employees are defined as large. A total of 500 individuals were contacted to participate in the research, and a total of 326 participated and completed the survey ( $65 \%$ response rate from the contacted firms). This indicates that the sampling procedure was effective and that the respondents perceived the research as relevant and worthwhile. The respondents were asked to rate the extent of agreement with each statement based on a "five-point Likert scale" of 1 (strongly disagree) to 5 (strongly agree). Figure 9 shows the respondents' percentages to the survey from in the USA, UAE, Sweden, Denmark and Canada with different professions. Out of 326, 50 respondents were project managers with the highest representation of $20.25 \%$ and contributing to the USA survey, 26 respondents. Fifty respondents were construction managers having the lowest representation of $15.34 \%$ and contributing to the survey from Denmark, which is six

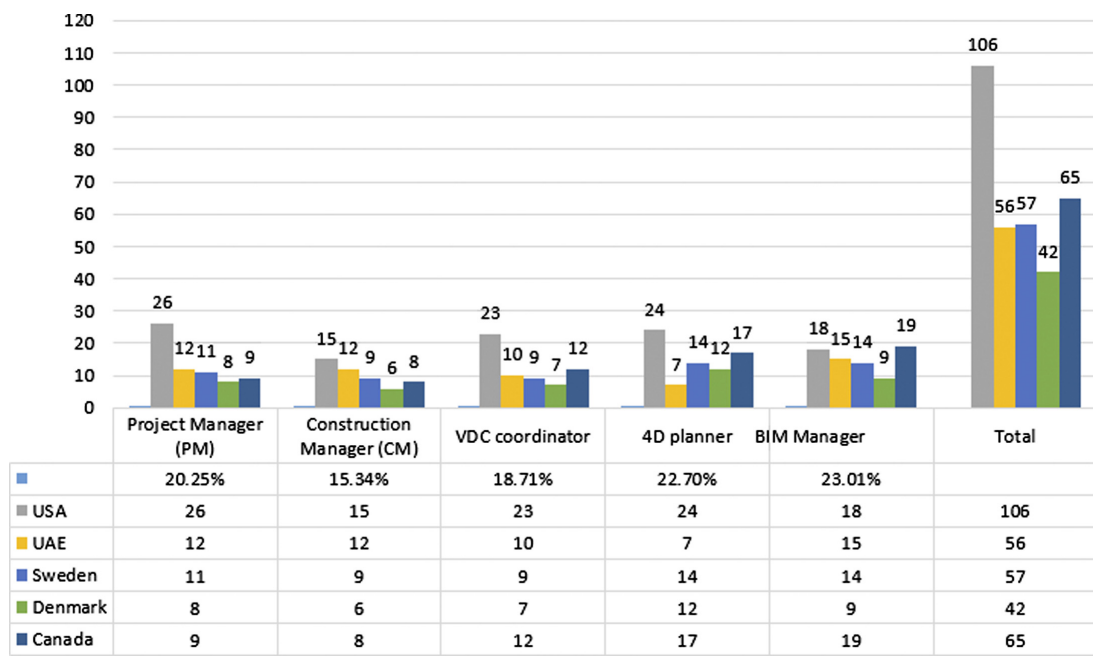

To develop a generic framework of a DT

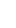


SASBE 12,1

\section{0}

respondents. The hypotheses regarding the contingent and direct effects were tested utilizing the collected data by the survey.

\subsection{Analysis of findings}

LISREL 8.8 statistical software package has been used to test and examine the hypothesized models, as shown in Figure 8. First, "Descriptive statistics and Pearson correlation coefficients" were calculated. Then the SEM was analyzed, a statistical methodology that takes a hypothesis-testing approach to analyze a structural theory's bearing on some phenomenon. SEM's basic steps include "specifying a model based on theory, determining how to measure constructs, collecting data, and analyzing data that include overall model fit statistics and parameter estimates". The model analysis specifies how latent variables or hypothetical constructs depend upon or are indicated by the observed variables. To measure the validity of the constructed model and the fit and suitability of the assumed causal relationships to the actual data, "Goodnessof- Fit Index (GFI)", "Adjusted Goodness-of-Fit Index (AGFI)", "Comparative Fit Index (CFI)", "Normed Fit index (NFI)", "Non-Normed Fit Index (NNFI)" and "Root-Mean-Square Error of Approximation (RMSEA)", and the ratio of "Chi-square" to the "Degree of Freedom" $\left(\chi^{2} / d f\right)$ were used. Goodness-of-fit indices evaluate whether the assumed model fits the empirical data, so they are significant indicators of the validity and reliability of the model.

\subsection{Descriptive statistics}

Table 5 demonstrates the means and standard deviations, as well as the inter-factor correlation matrix, for the study variables with the aim of valuating the significance level of the relationships. Pearson correlation analysis was used to validate the interrelationships between the dependent and independent variables tested in this study. All of the constructs are interrelated and focus on "AEC Digital Technologies", "4D Building Information Modeling (BIM)", "Digital Twins (DT)" and "Automated project progress monitoring". A $\rho$ value can express the significance of a relationship. When the $\rho$ value is $<0.05$, the relationship between the two sets of ratings is considered to be significant. The correlation matrix examination points which there were notable and positive linear associations between factors representing the variables "AEC Digital Technologies", "4D Building Information Modeling (BIM)", "Digital Twins” and "Automated project progress monitoring”.

4.3.2 SEM analysis and goodness-of-fit test. SEM techniques were utilized to perform the path analyses that helped test the relationships between the model constructs (hypotheses) and the model's goodness of fit (Kumar et al., 2020). The results showed that all standardized loadings on the relative constructs were greater than $0.5(\rho<0.001)$. The overall fit of the model was significant $\left(\chi^{2}=169.23\right.$ with $\left.d f=89 ; \rho<0.01\right)$. The resulting goodness-of-fit statistics revealed that comparative fit index $(\mathrm{CFI})=0.933$, GFI $=0.918$, AGFI $=0.913$, $\mathrm{NFI}=0.926, \mathrm{NNFI}=0.922$ and root-mean-square error of approximation (RMSEA) $=0.066$. The reason behind using different packages is that if the vast majority of the indexes indicate a good fit, then there is probably a good fit. The results of the GFI, AGFI, CFI, NFI and NNFI

Table 5.

Descriptive statistics and Pearson Correlation analysis

\begin{tabular}{lcccccr}
\hline Variables & Mean & SD & 1 & 2 & 3 & 4 \\
\hline AEC digital technologies & 4.83 & 0.84 & 1.000 & & & \\
4D building information modeling (BIM) & 4.84 & 0.86 & $0.627 * *$ & 1.000 & & \\
Digital twins & 4.85 & 0.88 & $0.683^{* *}$ & $0.705^{* * *}$ & 1.000 & \\
Automated project progress monitoring & 4.86 & 0.89 & $0.724^{* * *}$ & $0.748^{* * *}$ & $0.769 * * *$ & 1.000 \\
Note(s): $* \rho<0.1, * * \rho<0.05, * * * \rho<0.01, n=326$ & & & & & \\
\hline
\end{tabular}


exceeded the threshold value of 0.90 , and the hypothesized model revealed a good fit. A ratio of model fit statistics based on degrees of freedom below 3 indicates an adequate model fit $\left(\chi^{2} / d f=1.893\right)$. The hypothesized model in Figure 8 , thus, can be classified as closely fitting the data. Table 6 lists the results of the goodness-of-fit measures for the hypothesized model. Overall, goodness-of-fit measures all indicate very favorable fitness judgments for the hypothesized model.

4.3.3 Hypothesis test. To test Hypotheses 1 through 4, the hypothesized model was tested using "LISREL 8.8", where the paths between the AEC digital technologies and 4D building information modeling (BIM) (H1), 4D building information modeling (BIM) and automated project progress monitoring (H2), 4D building information modeling (BIM) and digital twins (H3), digital twins and automated project progress monitoring (H4) were estimated. The hypotheses regarding the relationships were tested based on the "associated $t$ statistics". " $T$ values exceeding" $1.65,1.98$ or 2.576 were considered significant at the $0.10,0.05$ and 0.01 levels, respectively. AEC digital technologies, $4 \mathrm{D}$ building information modeling (BIM) and digital twin all significantly and positively influenced $(\rho<0.05)$ automated project progress monitoring (with values of $\mathrm{H} 1=0.82, t$ value $=4.72, \mathrm{H} 2=0.83, t$ value $=4.75, \mathrm{H} 3=0.84$, $t$ value $=4.78$, and $\mathrm{H} 4=0.85, t$ value $=4.80$, respectively). Thus, hypotheses 1 through 4 were supported. Table 7 lists the results of the parameter estimates of the hypothesized model. Considering the standardized parameter estimates, the results show that four hypothesized relationships were classified as significant and accepted.

"Digital Twins - Automated project progress monitoring" had the highest significance with a path coefficient of 0.85 , revealing that $4 \mathrm{D}$ BIM data administration modeling procedures contribute to digital twin attainment. "4D Building Information Modeling (BIM) - Digital Twin" had the second highest significance with a path coefficient of 0.84 , revealing that 4D BIM data administration methods provide an incentive to enhance digital progress monitoring. Table 8 lists the "standardized structural coefficients" of the variables, AEC

\begin{tabular}{llcl}
\hline Statistics & \multicolumn{1}{c}{ Fitness criteria } & Values & Fitness judgment \\
\hline$\chi^{2}$ & $\rho<0.01$ & $169.23(\rho=0.000<0.01)$ & Yes \\
RMSEA & $<0.08(<0.05$ is excellent, and $<0.08$ is good) & 0.066 & Yes (good) \\
GFI & $>0.90$ & 0.918 & Yes \\
AGFI & $>0.90$ & 0.913 & Yes \\
NFI & $>0.90$ & 0.926 & Yes \\
NNFI & $>0.90$ & 0.922 & Yes \\
CFI & $>0.90$ & 0.933 & Yes \\
$\chi^{2} / d f$ & $<2.00$ & 1.893 & Yes
\end{tabular}

To develop a generic framework of a DT

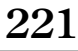

\begin{tabular}{|c|c|c|}
\hline Hypothesized model & $\begin{array}{l}\text { Parameter } \\
\text { coefficient }\end{array}$ & $t$-value \\
\hline \multicolumn{3}{|l|}{ Construct relationship } \\
\hline H1: AEC digital technologies $\rightarrow$ 4D building information modeling (BIM) & $0.82 * *$ & 4.72 \\
\hline $\begin{array}{l}\mathrm{H} 2 \text { : } 4 \mathrm{D} \text { building information modeling }(\mathrm{BIM}) \rightarrow \text { automated project progress } \\
\text { monitoring }\end{array}$ & $0.83 * *$ & 4.75 \\
\hline H3: 4D building information modeling $(\mathrm{BIM}) \rightarrow$ digital twins & $0.84 * * *$ & 4.78 \\
\hline H4: Digital twins $\rightarrow$ automated project progress monitoring & $0.85^{* * * *}$ & 4.80 \\
\hline \multicolumn{3}{|c|}{$\begin{array}{l}\text { Note(s): Fit Indices: } \chi^{2}=169.23, d f=92, \chi^{2} / d f=1.893 \mathrm{GFI}=0.918, \mathrm{CFI}=0.933, \mathrm{AGFI}=0.913, \mathrm{NFI}=0.926 \text {, } \\
\text { NNFI }=0.922, \mathrm{RMSEA}=0.066 \\
* * \rho<0.05 \text {, and } * * * \rho<0.01\end{array}$} \\
\hline
\end{tabular}

Table 6

Overall goodness-of fit measures for the hypothesized model

$\rho * 0.05$, and $* * * \rho<0.01$

Table 7.

Parameter estimates for SEM 
SASBE

12,1

\section{2}

4D building information modeling (BIM)

(Alizadehsalehi and Yitmen, 2019; Braun et al., 2018, 2020; Golparvar-Fard et al., 2009, 2015; Kropp et al., 2018; Puri and Turkan, 2020; Tuttas et al., 2017)

Digital twins (Aheleroff et al., 2020; A1Sehrawy \& Kumar, 2020; Boje et al., 2020; Bosch-Sijtsema et al., 2021; Dawood et al., 2020; Götz et al., 2020; Lin and GolparvarFard, 2020; Lu et al., 2020; Meža et al., 2021; Pan and Zhang, 2021; Sommer et al., 2019)

Automated project progress monitoring (Braun et al., 2020; Golparvar-Fard et al., 2009; Lin and Golparvar-Fard, 2020; Puri and Turkan, 2020; Rahimian et al., 2020)

Table 8.

Parameters and relationships

Note(s): $* * * \rho<0.01$

Standardized

Observed variables/ indicators

structural coefficient

3D laser scanning (LS) Image-based modeling Wireless sensor (WS) Simulation and virtual reality (VR)

Mobile interfaces and augmented reality (AR)

Mixed reality (MR)

Creating 3D geometric

object-based model data

Creating 3D as-built data

Identify parametric

features in 3D model

Data sorting and

categorizing

Creating sequencing and

schedule data

Data connection

$4 \mathrm{D}$ visualization and

simulation

Clash detection

Data integration

Data management

Intelligent decision-

making

Optimization operation

Data analysis

Feedback driving

Digital mapping

Data fusion

Diagnosis

Computing

Self-learning

Prognosis

Redesign

Perception

Environmental condition

data

Physical data collection

Remote inspection

Remote decision-making

Data management

Monitoring time

Monitoring quality

Monitoring cost

Automation

Practical

Future potential

Stakeholder satisfaction

Communication quality

Collaboration

performance
$0.84 * * *$

$0.81^{* * * *}$

$0.78 * *$

$0.83^{* * * *}$

$\lambda_{3}$
$\lambda_{4}$

$0.82^{* * * *}$

$\lambda_{5}$

$0.79 * *$

$\lambda_{6}$

$0.81 * * *$

$\gamma_{1}$

$\begin{array}{ll}\gamma_{2} & 0.82^{* * * *} \\ \gamma_{3} & 0.80^{* * * *}\end{array}$

$\gamma_{4} \quad 0.79 * *$

$\gamma_{5}$

$0.83^{* * * *}$

$\begin{array}{ll}\gamma_{6} & 0.79 * * \\ \gamma_{7} & 0.84 * * *\end{array}$

$\gamma_{7}$

$\begin{array}{ll}\gamma_{8} & 0.85 * * * \\ \beta_{1} & 0.85 * * *\end{array}$

$\begin{array}{ll}\beta_{1} & 0.84^{* * * *} \\ \beta_{2} & 0.86^{* * *}\end{array}$

$\beta_{3} \quad 0.86^{* * * *}$

$\beta_{4} \quad 0.82^{* * * *}$

$\beta_{5} \quad 0.81^{* * * *}$

$\beta_{6} \quad 0.85^{* * * *}$

$\beta_{7} \quad 0.84^{* * * *}$

$\beta_{8} \quad 0.83^{* * * *}$

$\beta_{9} \quad 0.86^{* * * *}$

$\beta_{10} \quad 0.83^{* * * *}$

$\beta_{11} \quad 0.86^{* * * *}$

$\beta_{12} \quad 0.82^{* * * *}$

$\beta_{13} \quad 0.81^{* * * *}$

$\beta_{14} \quad 0.84^{* * * *}$

$\omega_{1} \quad 0.83^{* * * *}$

$\omega_{2} \quad 0.84^{* * * *}$

$\omega_{3} \quad 0.81^{* * * *}$

$\omega_{4} \quad 0.85^{* * * *}$

$\omega_{5} \quad 0.82^{* * * *}$

$\omega_{6} \quad 0.83 * * *$

$\omega_{7} \quad 0.82^{* * * *}$

$\omega_{8} \quad 0.83^{* * * *}$

$\omega_{9} \quad 0.86^{* * * *}$

$\omega_{10} \quad 0.80^{* *}$

$\omega_{11} \quad 0.82^{* * * *}$

$\omega_{12} \quad 0.84^{* * * *}$

$\omega_{13} \quad 0.80^{* *}$

$\omega_{14} \quad 0.85^{* * * *}$ 
digital technologies, 4D building information modeling (BIM), digital twins and automated project progress monitoring representing the magnitudes that reflect the relative importance of the relationships with their identified important references. The variables "Automation", "Self-learning", "Diagnosis", "Intelligent decision-making", "Remote decision-making", "Clash detection", "Data integration", "Feedback driving" and "Collaboration performance" with values of $0.87,0.87,0.87,0.87,0.86,0.86,0.86$ and 0.86 have the highest factor loading, respectively. Most significantly, the high path coefficient values in the structural model validate the empirical modeling work.

Hypothesis 1: It posits that leveraging of AEC digital technologies facilitates the generation and simulation of the 4D BIM model. As presented in Figure 8, the path coefficients of 0.82 , which describe the hypothesized model relationships, were statistically positive and significant. H1 implies which various reality capture technologies such as laser scans and sensors can improve the accuracy and timeliness of the data collected from sites to generate and simulate the 4D BIM model. The process can be significantly improved by utilizing and combining the captured data with BIM as an effective visualization, modeling and management source. This combination yields a collection of accurate, complete and reliable field data models from the architectural, structural and MEP part of any construction project.

Hypothesis 2: It posits that utilizing 4D BIM simulations enhance automated project progress monitoring. As presented in Figure 8, the path coefficients of 0.83 , which describe the hypothesized model relationships, were statistically positive and significant. This proposes that, when a high-level $n-D$ as-planned model of the work to be tracked is available, the previous data included in the model can be leveraged for automated progress monitoring. The level at which the developed 4D model gives access to accurate information at the correct time and in the precise place is pivotal for decision-making and ensuring that a project is delivered according to pre-defined parameters established at its onset. Provide a consistent platform for representing as-built, as-planned and progress discrepancy data that facilitates communication and reporting methods. It is used to visualize the architectural, structural and MEP parts at any stage of project monitoring. This progress monitoring level leads to a unified system for a more robust automated comparison of as-planned and as-built data.

Hypothesis 3: It posits that the facilitating 4D BIM models constitute the generation of digital twins. As displayed in Figure 8, the path coefficients of 0.84 , which describe the hypothesized model relationships, were statistically positive and significant. This proposes that advancing in 4D BIM integrated with digital twins, that is the underline and federate for digital construction help to synchronize their changes and keep them up-to-date with the changing reality of the assets as the project progress. DTs offer a key, analytic edge to BIM systems. By amassing data from various sources and combining them with an $n$ - $D$ model, construction team members get vital access insight into each component. With the aid of DT abilities, BIM models are evolving to become "living," automatically updated representations of physical assets they represent. BIM creates a $n-D$ virtual model of project that it contains much of the information that a digital twin would require.

Hypothesis 4: It posits that the digital twins enrich the simulated data and empowers the performance of automated project progress monitoring. As shown in Figure 8, the path coefficients of 0.85 , which describe the hypothesized model relationships, were statistically positive and significant. This proposes that the 4D BIM creating the perfect basis for a digital twin platform. Real-time automated progress monitoring analysis based on actual operating conditions can be undertaken by incorporating real-time data like laser scanners, digital cameras and/or sensors. While 4D BIM provides procedures, technologies and data schemas facilitating a standardized semantic representation of construction projects components/ systems, the DT conveys a more holistic process-oriented characterization of the complex management and optimization process by leveraging data flows for automated construction 
SASBE 12,1

project progress monitoring. This system provides superior performance, enabling automated and robust progress control and delivering accurate as-built BIM models to project stakeholders.

\section{Discussion and implications}

\subsection{Theoretical contributions}

This research attempted to introduce a framework for enhancing the automation of progress monitoring and control of construction projects' types and sizes. Due to the capability of the emerging technologies and methodologies for capturing and integrating data from the construction site, this research developed and introduced a DRX management model. The developed system DRX integrates all the proposed technologies currently existing, but is on their path of evolution. The proposed DRX model gathered these technologies from different domains, which each can address and solve some part of identified construction progress monitoring gaps of AEC industry. This research contributed to how these emerging technologies work collaboratively together as a DRX system to create, capture, analyze, manage and visualize construction progress data, information and reports.

This research has made a contribution toward developing a DRX project progress management model based on process modeling and IDEF0 language; developing a guideline of using various available technologies within the framework of DRX and examining the importance, strengths and challenges of DRX model. DRX is able to optimize data and information for the decision-making process at the pre-construction stage; capture precise, real-time, and comprehensive data at the construction stage; create a CDE for all created data at the pre-construction stage and captured data at construction stage; analyze data and information based on the requirements of any type and size of a construction project; visualize information and reports in a real scale environment at any stages of a project; facilitate data and information flows and communication; constant reality feedback to plan; provide visual verification; learn from itself, historical data and accessible online data to predict the reliability of plans and optimize decision-making process.

Another significance of the current study would be the detailed outcome of all the developed DRX model's executive processes. This comprehensive model is entirely ready to adapt in terms of integrability and operability to a BIM platform to be used by AEC professionals.

The findings at this research are consistent with the previous studies and author's assumptions regarding DRX model of framework. Supporting the automated assessment of construction projects in progress utilizing extensive acquisitions of site information has the potential to improve the productivity of construction project monitoring significantly (Dinis et al., 2020; Puri and Turkan, 2020; Sanhudo et al., 2020). Many of the engineering managers, in discussions regarding this research, noted that field data capturing technologies like laser scanner, digital camera and wireless sensors have high positive influences in the progress monitoring of construction projects. They believe that advancement in automatic field data acquisition systems will enable more accurate collection of data and knowledge about processes and operations on site. Nevertheless, these procedures for taking site information do not support the desired results or completeness for automated progress monitoring (Alizadehsalehi and Yitmen, 2019). With the advancement in processing, sensing, computer technologies and communication capabilities of reality capturing technologies, they have become more affordable and modern remote sensing systems for construction projects progress monitoring (Han et al., 2018; Omar and Nehdi, 2016; Pučko et al., 2018). This indicates that progress monitoring has the ability to fully and automatically capture data, except the technologies need an approach to be completed. These cutting-edge technologies offer diverse advantages in supporting construction site monitoring. This endorses the scope of the use of 
field data capturing technologies for automated project progress monitoring, as described above.

The findings are congruent with the literature. To accomplish the information-based integrated construction project management system, automated progress measurement is necessary (Alizadehsalehi and Yitmen, 2019). On-time, accurate and efficient progress monitoring is required for a construction management system to move forward and be operative and productive. A systematic, well-organized and comprehensive approach/ framework for progress monitoring needs to be developed to manage project progress effectively (Braun et al., 2020; Lin and Golparvar-Fard, 2020; Puri and Turkan, 2020). Current different BIM-based field data capturing technologies are perhaps the most notable change in progress monitoring. The BIM-based automated progress monitoring systems utilize the collected 4D/BIM-based as-built data and compare it with the 4D/BIM-based as-designed data to recognize the discrepancies between them well-interpreted approach. This timely and efficient data analysis and visualization of differences between 4D/BIM-based as-built data and 4D/BIM-based as-designed data in an early step provide possibilities to prevent potential expected delays and enable appropriate corrective actions. This indicates that project managers need a robust monitoring method/system that assures the most updated design, up-to-date schedule, cost and progress performance data delivered and presented in a timely and comprehensive way. That supports the scope of the BIM-based field data capturing technologies for the automated project progress monitoring described previously.

The findings are congruent with literature in that for construction progress monitoring, using DT proposes always having access to as-planned and as-built data and models that are synced continuously in real-time (Boje et al., 2020; Braun et al., 2020; Kan and Anumba, 2019). BIM provides technologies, procedures and data schemas to facilitate a standardized semantic representation of building systems. A DT is a connection between a real-world object and its digital representation, which consistently utilizes data from data-capturing technologies and various sensors located on a job site to establish a virtual object's representation (Boje et al., 2020). It conveys a more holistic socio-technical and processoriented characterization of the complex artifacts involved by leveraging the cyber-physical bi-directional data flows' synchronicity. Furthermore, BIM lacks semantic completeness in areas such as control systems, including sensor networks, social systems and urban artifacts beyond buildings' scope, thus requiring a holistic, scalable semantic approach that factors in dynamic data at different levels (Braun et al., 2020). This allows project stakeholders to continuously monitor the project's progress versus the schedule laid out in a 4D-BIM model. This also provides the model predictive control/monitoring method to make the best decisions with forwarding simulation, beginning with the project's current state (Rahimian et al., 2020). Therefore, project stakeholders can continuously analyze various ways of operations and estimate/determine their corresponding cost functions and probabilities to pick the most optimal judgment/decision (or adjustment) for what they must do next.

The findings are consistent with the literature in that transforming complex data into simple and straightforward XRs visualizations environment gives context to critical information on the job site (Alizadehsalehi et al., 2020; Kopsida and Brilakis, 2020; Lin et al., $2019 \mathrm{~b})$. With BIM-to-XR workflow provides interactive visualization of the proposed design with an immersive experience and human scale. Users can interact with the 3D information model on top of the physical space by either superimposing the different design options within the existing job site condition or reading additional information that does not exist in the real-world (Alizadehsalehi et al., 2020). The visualization of complex data/model with XR technologies makes it easy to observe spatial relationships more precisely to recognize and mitigate structural and MEP clashes earlier. XR technologies enhance construction projects' profitability and productivity by facilitating collaborative communication among project team members and other stakeholders (Boje et al., 2020). They visually recognize issues and 
SASBE

12,1

\section{6}

make informed decisions to resolve the problems in real-time, on-site. XR technologies are emerging to digitalize the AEC industry, making it significantly more productive and effective. Construction management teams will have better construction schedule control and decision-making through the DRX system, saving money and time for a modular construction project. This process needs a system to share data and collaboration information and enable real-time communication between various users.

The findings reinforce the literature that precise and effective monitoring, analysis and visualization of a project's structural parts of as-built state ongoing projects are key components of effective project evaluation (Alizadehsalehi et al., 2020; Kan and Anumba, 2019; Lin and Golparvar-Fard, 2020). DTs give project team members access to as-built and as-planned BIM models that are continuously synced in real-time. DRX is advancing rapidly beyond $n-D$ BIM and DT, due to the confluence of $4 \mathrm{D}$ visualization, reality capturing technologies, XRs, providing an immersive and integrated view of all infrastructure assets above ground, on the surface and below ground to observe and monitor. With cognitive computing applications like AI and ML and computing analytics, projects provide insights and analytics visibility to improve progress monitoring processes more effectively with anticipating issues before they arise and react more swiftly with confidence. In the form of the DRX model, these technology integrations envisage the automation of monitoring tasks through a real-time DT, enabling experts to conduct inspections remotely, vastly increasing productivity and leveraging scarce knowledge resources. This provides all project stakeholders to continuously monitor progress against the schedule laid out in a 4D/BIMbased environment precisely and comprehensively.

\subsection{Managerial implications}

The DRX system presented in this research automates and enhances the time-consuming management task's accuracy by capturing fast and precisely, computing construction progress process, updating project information automatically, presenting in a real scale and transferring reports and data quickly by cloud. The quantitative analysis of the data collected from 326 project managers, construction managers, VDC coordinators, 4D planners and BIM managers indicates that there is a willingness to use the DRX model of management. Based on the result of this analysis, clash detection, data integration, intelligent decision-making, feedback driving, diagnosis, self-learning, remote decision-making, automation and collaboration performance are the essential features of the DRX model. The summary of the strengths and challenges of the proposed system based on literature review, author's experiences and construction management specialist are shown in Table 9.

\section{Conclusions}

This study presented an automated construction progress monitoring system called DRX. The integration of BIM, various reality capturing technologies (laser scanner and wireless sensors), DT and XR technologies (VR, AR, and MR) have been shown by IDEF0 modeling. It arrays steps on how these technologies work collaboratively to create, capture, generate, analyze, manage and visualize construction progress data, information and reports. The SEM method has been used to test the proposed hypotheses and develop the skill model to examine the reliability, validity and contribution of the framework to understand the DRX model's effectiveness if implemented in real practice. Finally, this research highlighted the strengths and challenges of DRX. As a core part of the DRX system, DT helps manage, simulate, analyze as-planned and as-built data and optimize and predict a project's functionality in various scenarios. With the aid of data and feedback, both physical and simulated models can develop autonomy and learn from their environments. However, this implementation will 


\begin{tabular}{|c|c|c|}
\hline Strength and challenges & Brief explanation & I o develop a \\
\hline \multirow{5}{*}{ Strengths } & Cost & framework of a \\
\hline & Reduced manpower required for progress status capture on site & mamework ol d \\
\hline & Reduced manpower required for recording captured data in the office & \\
\hline & Reduced cost of errors and recaptured data & \\
\hline & Gives client more necessary info and confidence when selecting contractors & \\
\hline \multirow{4}{*}{ Challenges } & $\begin{array}{l}\text { Reduced cost of management plan } \\
\text { Reduced cost of change control }\end{array}$ & 227 \\
\hline & Cost of purchasing RC-to-BIM, BIM-to-XR and DT software & \\
\hline & Cost of purchasing UAV, camera, sensors and XR technologies & \\
\hline & Cost of software and hardware upgrading & \\
\hline & Cost of additional time to design and implement DRX progress model & \\
\hline & Cost of hiring additional employees to implement BIM by designers & \\
\hline & Cost of hiring engineering team (computer science) & \\
\hline & Cost of training of existing employees in the office and onsite & \\
\hline & Cost of hiring additional employees to implement the DRX system & \\
\hline & Cost of additional time to design the DRX design model & \\
\hline & Cost of hiring reality capturing team to capture data & \\
\hline \multirow{18}{*}{ Strengths } & Quality & \\
\hline & Capturing all blind points of the project & \\
\hline & Automation of progress control process & \\
\hline & Construction progress rule and code checking & \\
\hline & Early progress planning on pre-construction stage & \\
\hline & Monitoring worker motion and worker location & \\
\hline & Automatic layout of as-planned and as-built & \\
\hline & Better understanding of project & \\
\hline & Identification of potential quality collapse & \\
\hline & High quality progress meeting with all visualization information & \\
\hline & Reduced information loss in data exchange & \\
\hline & Automatic identification of quality issues & \\
\hline & Real-time checking of progress conditions & \\
\hline & Reduced personnel safety hazards & \\
\hline & Better monitoring of physical environments (equipment) & \\
\hline & Improved construction management & \\
\hline & Easily changed work practices & \\
\hline & Allows a human-scale clearance check & \\
\hline \multirow[t]{10}{*}{ Challenges } & Lack of integration of progress monitoring rule checking into BIM & \\
\hline & Decision-making process still needs human input and can be error prone & \\
\hline & Lack of trust to comparing as-built and as-planned data by current algorithms & \\
\hline & Lack of fully automated system & \\
\hline & Different levels of visual training & \\
\hline & UAV is easy to fall due to incompetent operator & \\
\hline & UAV is easy to fall due to strong wind & \\
\hline & The remote-control signal is interfered/blocked by other radio signals or obstacle & \\
\hline & UAV may distract the attention of workers and may cause more accidents & \\
\hline & Time & \\
\hline \multirow[t]{9}{*}{ Strengths } & Real-time and quick monitoring of progress (paperwork eliminated) & \\
\hline & Real-time and quick reporting of physical conditions & \\
\hline & Real-time and quick reporting of quality conditions & \\
\hline & Real-time reporting of progress status & \\
\hline & Quick progress issues reporting and investigation & \\
\hline & Progress control regulated in contract documents & \\
\hline & Real-time reporting of sources of progress issues & \\
\hline & Tests the feasibility of an architectural design & \\
\hline & Permits real-time virtual collaboration for stakeholders from different locations & \\
\hline \multirow[t]{5}{*}{ Challenges } & Long hours to develop a BIM model & Table 9. \\
\hline & Lack of authority and procedures for UAV operations & Strengths and \\
\hline & Lengthy training of employees in BIM, LS, WS, XR and DT skills & challenges of DRX \\
\hline & Long time needed to create rules, procedures, and policies & progress monitoring \\
\hline & Cumbersome public policy for getting license to fly UAVs in project area & \\
\hline
\end{tabular}


SASBE

12,1

require overcoming numerous obstacles of technological, organizational, commercial and sociological. DT has promising applications within the DRX system, which can help design precise as-planned models, collect more accurate data, compare as-planned and as-built models and verify that the completed work is consistent with plans and specifications. DRX provides trustable, real-time, transparent and digital data/information/reports that will be helpful for:

(1) Creating high-quality designs (as-planned models): create a design model, and visualization is a kind of loop that help designer to draw, visualize and check the design through XR technologies and get a high-quality design. This part of the DRX management system helps all stakeholders of the projects such as clients, project managers and designers to check the model step by step, find out its issues and compare different design scenarios to get the highest quality design and the first step of the project.

(2) Planning and optimizing various scenarios (as-planned models): as a complete high fidelity digital representation of a physical asset, DRX with DT provides a safe, reliable environment to study, inspect and test various scenarios and optimize strategies before implementation at the job site.

(3) Capturing accurate, real-time and comprehensive data at construction stage (as-built models): DRX, with the help of various types of reality capturing technologies such as laser scanner, cameras and sensors, in construction stage, can capture precisely, real-time and comprehensive as-built data from the timely status of construction projects based on the pre-defined progress monitoring plan.

(4) Analyzing data and information precisely and quickly (as-planned and as-planned models): DRX included DT as a powerful and intelligent engine to manage, analyze and simulate these created and captured data for analyzing data and information precisely and quickly, which is connected to historical data and work with cognitive computing and computing analytics.

(5) Visualizing information and reporting in a real scale environment (as-planned and as-planned models): DRX, with the help of XR technologies (VR, AR and MR), which is in the data access part of it, can visualize created and captured data and information in a real scale environment. Immersing in this environment allowed involved stakeholders to virtually walk on the project, evaluate the model and give the designer comments to improve the system.

(6) Facilitating information flows and communication (as-planned and as-planned models): in the context of the DRX model of management, the system facilitates information flows and communication between as-planned and as-planned models.

(7) Learning from itself, historical data and accessible online data to predict future actions: a DRX system with DT continuously learns and updates itself from multiple sources such as itself, historical data belongs to the company, municipality or regulations, or online data and to represent its near real-time status, working condition or position. DRX is able to predict future actions.

(8) Providing semantic and digitalize construction information with analytical capabilities: DRX converts the captured and created data into semantic concepts, meaningful translations of the data and thereby bridge the semantic gap between the computer and humans with the advantage of novel technologies that are meaningful for construction projects. 
(9) Increasing the vision: empower complex construction systems to be intelligently operated with transparency and while also gaining valuable insights that we need to operate these systems to their highest efficiency level.

(10) Optimizing decision-making process: DRX helps in creating and collecting as much data from pre-construction, construction and historical data as possible and trying to find the optimal choice. Novel technologies at DRX let the decision-makers have the opportunities to select the best scenarios from various accepted and high-quality models and scenarios.

\subsection{Future research}

The body of results shows the applicability of the DRX integration for a variety of AEC analysis scenarios, and it proves the high eventual added value that a DRX would convey. DRX automation system provides the answer to the DT concept requirements in Industry 4.0 deployments. The benefits of DRX to the AEC industry will be long-term, from a lean and BIM construction process toward smart, dynamic and semantic AEC management systems. Reality capturing technologies such as laser scanners, UAV-based cameras, sensors, besides XR technologies have proved to be reliable and safe, yet effective options in an industry that is consistently evolving and integrating novel emerging technologies. In addition, with the help of cognitive computing, AI, ML and 5G network associated with future hardware and software advancements, BIM and DT-based systems will be more widely applied in the AEC industry.

Further research is required to establish methodologies and best practices for current and future DRX integration in AEC manners. Using this system's legal and financial aspects will also lead to future research of DRX and its integration in the AEC domain. Future research will also implement this framework on multiple construction projects to analyze the existing and emerging examples of DRX applications by utilizing objective data to evaluate the longterm impact of DRX in construction operations.

\section{References}

Aheleroff, S., Xu, X., Zhong, R.Y. and Lu, Y. (2020), "Digital twin as a service (DTaaS) in industry 4.0: an architecture reference model”, Advanced Engineering Informatics, Vol. 47, p. 101225, doi: 10. 1016/j.aei.2020.101225.

Al-Sehrawy, R. and Kumar, B. (2020), "Digital twins in architecture, engineering, construction and operations. A brief review and analysis", International Conference on Computing in Civil and Building Engineering, Springer, doi: 10.1007/978-3-030-51295-8_64.

Alizadehsalehi, S. and Yitmen, I. (2016), "The impact of field data capturing technologies on automated construction project progress monitoring", Procedia Engineering, Vol. 161, pp. 97-103, doi: 10.1016/j.proeng.2016.08.504.

Alizadehsalehi, S. and Yitmen, I. (2019), “A concept for automated construction progress monitoring: technologies adoption for benchmarking project performance control", Arabian Journal for Science and Engineering, Vol. 44 No. 5, pp. 4993-5008, doi: 10.1007/s13369-018-3669-1.

Alizadehsalehi, S., Hadavi, A. and Huang, J.C. (2019a), "BIM/MR-Lean construction project delivery management system”, 2019 IEEE Technology and Engineering Management Conference (TEMSCON), IEEE. doi: 10.1109/TEMSCON.2019.8813574.

Alizadehsalehi, S., Hadavi, A. and Huang, J.C. (2019b), Virtual Reality for Design and Construction Education Environment, AEI 2019American Society of Civil Engineers, Reston, VA, pp. 193-203, doi: 10.1061/9780784482261.023.

Alizadehsalehi, S., Hadavi, A. and Huang, J.C. (2020), "From BIM to extended reality in AEC industry", Automation in Construction, Vol. 116, p. 103254, doi: 10.1016/j.autcon.2020.103254. 
SASBE 12,1

Almukhtar, A., Saeed, Z.O., Abanda, H. and Tah, J.H. (2021), "Reality capture of buildings using 3D laser scanners", CivilEng, Vol. 2 No. 1, pp. 214-235, doi: 10.3390/civileng2010012.

Alonso, R., Borras, M., Koppelaar, R.H., Lodigiani, A., Loscos, E. and Yöntem, E. (2019), "SPHERE: BIM digital twin platform”, Multidisciplinary Digital Publishing Institute Proceedings. doi: 10. 3390/proceedings2019020009.

Angjeliu, G., Coronelli, D. and Cardani, G. (2020), "Development of the simulation model for Digital Twin applications in historical masonry buildings: the integration between numerical and experimental reality", Computers and Structures, Vol. 238, p. 106282, doi: 10.1016/j.compstruc. 2020.106282.

Arif, F. and Khan, W.A. (2021), "Smart progress monitoring framework for building construction elements using videography-MATLAB-BIM integration", International Journal of Civil Engineering, Vol. ahead-of-print No. ahead-of-print, doi: 10.1007/s40999-021-00601-3.

Aryan, A., Bosché, F. and Tang, P. (2021), "Planning for terrestrial laser scanning in construction: a review", Automation in Construction, Vol. 125, p. 103551, doi: 10.1016/j.autcon.2021.103551.

Asadi, K., Haritsa, V.R., Han, K. and Ore, J.-P. (2021), "Automated object manipulation using visionbased mobile robotic system for construction applications", Journal of Computing in Civil Engineering, Vol. 35 No. 1, 04020058, doi: 10.1061/(ASCE)CP.1943-5487.0000946.

Azhar, S. (2017), "Role of visualization technologies in safety planning and management at construction jobsites", Procedia Engineering, Vol. 171, pp. 215-226, doi: 10.1016/j.proeng.2017. 01.329.

Behnam, A., Wickramasinghe, D.C., Ghaffar, M.A.A., Vu, T.T., Tang, Y.H. and Isa, H.B.M. (2016), "Automated progress monitoring system for linear infrastructure projects using satellite remote sensing", Automation in Construction, Vol. 68, pp. 114-127, doi: 10.1016/j.autcon.2016.05.002.

Boje, C., Guerriero, A., Kubicki, S. and Rezgui, Y. (2020), "Towards a semantic construction digital twin: directions for future research", Automation in Construction, Vol. 114, p. 103179, doi: 10. 1016/j.autcon.2020.103179.

Bosch-Sijtsema, P., Claeson-Jonsson, C., Johansson, M. and Roupe, M. (2021), "The hype factor of digital technologies in AEC", Construction Innovation. doi: 10.1108/CI-01-2020-0002.

Bosché, F., Guillemet, A., Turkan, Y., Haas, C.T. and Haas, R. (2013), "Tracking the built status of MEP works: assessing the value of a Scan-vs-BIM system", Journal of Computing in Civil Engineering, Vol. 28 No. 4, 05014004, doi: 10.1061/(ASCE)CP.1943-5487.0000343.

Bosché, F., Ahmed, M., Turkan, Y., Haas, C.T. and Haas, R. (2015), “The value of integrating Scan-toBIM and Scan-vs-BIM techniques for construction monitoring using laser scanning and BIM: the case of cylindrical MEP components", Automation in Construction, Vol. 49, pp. 201-213, doi: 10.1016/j.autcon.2014.05.014.

Braun, A., Tuttas, S., Stilla, U. and Borrmann, A. (2018), "Bim-based progress monitoring”, Building Information Modeling, Springer, pp. 463-476, doi: 10.1007/978-3-319-92862-3_28.

Braun, A., Tuttas, S., Borrmann, A. and Stilla, U. (2020), "Improving progress monitoring by fusing point clouds, semantic data and computer vision", Automation in Construction, Vol. 116, p. 103210, doi: 10.1016/j.autcon.2020.103210.

Camposano, J.C., Smolander, K. and Ruippo, T. (2021), "Seven metaphors to understand digital twins of built assets", IEEE Access, Vol. 9, pp. 27167-27181, doi: 10.1109/ACCESS.2021.3058009.

Chalhoub, J. and Ayer, S.K. (2018), "Using Mixed Reality for electrical construction design communication", Automation in Construction, Vol. 86, pp. 1-10, doi: 10.1016/j.autcon.2017. 10.028 .

Chalhoub, J., Alsafouri, S. and Ayer, S.K. (2018), "Leveraging site survey points for mixed reality BIM visualization", Construction Research Congress. doi: 10.1061/9780784481264.032.

Cheng, J.C., Chen, K. and Chen, W. (2020), "State-of-the-art review on mixed reality applications in the AECO industry", Journal of Construction Engineering and Management, Vol. 146 No. 2, 03119009, doi: 10.1061/(ASCE)CO.1943-7862.0001749. 
Chu, M., Matthews, J. and Love, P.E. (2018), "Integrating mobile building information modelling and augmented reality systems: an experimental study", Automation in Construction, Vol. 85, pp. 305-316, doi: 10.1016/j.autcon.2017.10.032.

Czerniawski, T., Ma, J.W. and Leite, F. (2021), "Automated building change detection with amodal completion of point clouds", Automation in Construction, Vol. 124, p. 103568, doi: 10.1016/j. autcon.2021.103568.

Dai, F., Olorunfemi, A., Peng, W., Cao, D. and Luo, X. (2021), "Can mixed reality enhance safety communication on construction sites? An industry perspective", Safety Science, Vol. 133, p. 105009, doi: 10.1016/j.ssci.2020.105009.

Davidson, J., Fowler, J., Pantazis, C., Sannino, M., Walker, J., Sheikhkhoshkar, M. and Rahimian, F.P. (2019), "Integration of VR with BIM to facilitate real-time creation of bill of quantities during the design phase: a proof of concept study", Frontiers of Engineering Management, pp. 1-8, doi: 10. 1007/s42524-019-0039-y.

Dawood, N., Pour Rahimian, F., Seyedzadeh, S. and Sheikhkhoshkar, M. (2020), "Enabling the development and implementation of digital twins", in Dawood, N., Pour Rahimian, F., Seyedzadeh, S. and Sheikhkhoshkar, M. (Eds), Proceedings of the 20th International Conference on Construction Applications of Virtual Reality, 30 Sep - 02 Oct 2020, Teesside University, Middleborough, pp. 1-9.

Deng, M., Menassa, C.C. and Kamat, V.R. (2021), "From BIM to digital twins: a systematic review of the evolution of intelligent building representations in the AEC-FM industry", Journal of Information Technology in Construction (ITcon), Vol. 26 No. 5, pp. 58-83, doi: 10.36680/j.itcon. 2021.005.

Dimitrov, A. and Golparvar-Fard, M. (2014), "Vision-based material recognition for automated monitoring of construction progress and generating building information modeling from unordered site image collections", Advanced Engineering Informatics, Vol. 28 No. 1, pp. 37-49, doi: 10.1016/j.aei.2013.11.002.

Dinis, F.M., Sanhudo, L., Martins, J.P. and Ramos, N.M. (2020), "Improving project communication in the architecture, engineering and construction industry: coupling virtual reality and laser scanning", Journal of Building Engineering, Vol. 30, p. 101287, doi: 10.1016/j.jobe.2020.101287.

Du, J., Zou, Z., Shi, Y. and Zhao, D. (2017), "Simultaneous data exchange between BIM and VR for collaborative decision making", Computing in Civil Engineering, Vol. 2017, pp. 1-8, doi: 10.1061/ 9780784480830.001.

Du, J., Zou, Z., Shi, Y. and Zhao, D. (2018), "Zero latency: real-time synchronization of BIM data in virtual reality for collaborative decision-making", Automation in Construction, Vol. 85, pp. 51-64, doi: 10.1016/j.autcon.2017.10.009.

El Saddik, A. (2018), "Digital twins: the convergence of multimedia technologies", IEEE Multi Media, Vol. 25 No. 2, pp. 87-92, doi: 10.1109/MMUL.2018.023121167.

Elghaish, F., Matarneh, S., Talebi, S., Kagioglou, M., Hosseini, M.R. and Abrishami, S. (2020), "Toward digitalization in the construction industry with immersive and drones technologies: a critical literature review", Smart and Sustainable Built Environment. doi: 10.1108/SASBE-06-2020-0077.

Garbett, J., Hartley, T. and Heesom, D. (2021), "A multi-user collaborative BIM-AR system to support design and construction”, Automation in Construction, Vol. 122, p. 103487, doi: 10.1016/j.autcon. 2020.103487.

Götz, C.S., Karlsson, P. and Yitmen, I. (2020), "Exploring applicability, interoperability and integrability of Blockchain-based digital twins for asset life cycle management", Smart and Sustainable Built Environment, Vol. ahead-of-print No. ahead-of-print, doi: 10.1108/SASBE-082020-0115.

Golparvar-Fard, M., Peña-Mora, F. and Savarese, S. (2009), "D4AR-a 4-dimensional augmented reality model for automating construction progress monitoring data collection, processing and communication", Journal of Information Technology in Construction, Vol. 14 No. 13, pp. 129-153, available at: http://www.itcon.org/2009/13. 
SASBE 12,1

\section{2}

Golparvar-Fard, M., Pena-Mora, F. and Savarese, S. (2015), "Automated progress monitoring using unordered daily construction photographs and IFC-based building information models", Journal of Computing in Civil Engineering, Vol. 29 No. 1, 04014025, doi: 10.1061/(ASCE)CP.1943-5487. 0000205.

Golparvar-Fard, M., Hoiem, D., Lin, J.J.-C., Han, K.I. and Degol, J.M. (2019), “Computation of point clouds and joint display of point clouds and building information models with project schedules for monitoring construction progress, productivity, and risk for delays", U.S. Patent Application No. $15 / 956,266$.

Greif, T., Stein, N. and Flath, C.M. (2020), "Peeking into the void: digital twins for construction site logistics", Computers in Industry, Vol. 121, p. 103264, doi: 10.1016/j.compind.2020.103264.

Guide, A. (2001), Project Management Body of Knowledge (Pmbok® Guide), Project Management Institute, Pennsylvania, PA.

Guven, G. and Ergen, E. (2021), "Tracking major resources for automated progress monitoring of construction activities: masonry work case", Construction Innovation. doi: 10.1108/CI-052020-0081.

Haggard, K.E. (2017), Case Study on Virtual Reality in Construction, available at: https:// digitalcommons.calpoly.edu/cmsp/54.

Hamledari, H., Sajedi, S., McCabe, B. and Fischer, M. (2021), "Automation of inspection mission planning using 4D BIMs and in support of unmanned aerial vehicle-based data collection", Journal of Construction Engineering and Management, Vol. 147 No. 3, 04020179, doi: 10.1061/ (ASCE)CO.1943-7862.0001995.

Han, K.K. and Golparvar-Fard, M. (2014a), "Automated monitoring of operation-level construction progress using 4D BIM and daily site photologs", Construction Research Congress Construction in a Global Network. doi: 10.1061/9780784413517.106.

Han, K.K. and Golparvar-Fard, M. (2014b), "Multi-sample image-based material recognition and formalized sequencing knowledge for operation-level construction progress monitoring", Computing in Civil and Building Engineering, pp. 364-372, doi: 10.1061/ 9780784413616.046.

Han, K.K. and Golparvar-Fard, M. (2017), "Potential of big visual data and building information modeling for construction performance analytics: an exploratory study", Automation in Construction, Vol. 73, pp. 184-198, doi: 10.1016/j.autcon.2016.11.004.

Han, K., Degol, J. and Golparvar-Fard, M. (2018), "Geometry-and appearance-based reasoning of construction progress monitoring", Journal of Construction Engineering and Management, Vol. 144 No. 2, 04017110, doi: 10.1061/(ASCE)CO.1943-7862.0001428.

Hasan, S.M., Lee, K., Moon, D., Kwon, S., Jinwoo, S. and Lee, S. (2021), "Augmented reality and digital twin system for interaction with construction machinery", Journal of Asian Architecture and Building Engineering, pp. 1-12, doi: 10.1080/13467581.2020.1869557.

Hou, L., Chi, H.-L., Tarng, W., Chai, J., Panuwatwanich, K. and Wang, X. (2017), “A framework of innovative learning for skill development in complex operational tasks", Automation in Construction, Vol. 83, pp. 29-40, doi: 10.1016/j.autcon.2017.07.001.

Hou, L., Wu, S., Zhang, G.K., Tan, Y. and Wang, X. (2021), "Literature review of digital twins applications in construction workforce safety", Applied Sciences, Vol. 11 No. 1, p. 339, doi: 10. 3390/app11010339.

Irizarry, J. and Costa, D.B. (2016), "Exploratory study of potential applications of unmanned aerial systems for construction management tasks", Journal of Management in Engineering, Vol. 32 No. 3, 05016001, doi: 10.1061/(ASCE)ME.1943-5479.0000422.

Kaewunruen, S. and Lian, Q. (2019), "Digital twin aided sustainability-based lifecycle management for railway turnout systems", Journal of Cleaner Production, Vol. 228, pp. 1537-1551, doi: 10.1016/j. jclepro.2019.04.156. 
Kan, C. and Anumba, C. (2019), "Digital Twins as the Next Phase of Cyber-Physical Systems in Construction”, Computing in Civil Engineering 2019: Data, Sensing, and Analytics, American Society of Civil Engineers Reston, VA, pp. 256-264, doi: 10.1061/9780784482438.033.

Khairadeen Ali, A. and Park, C. (2020), "Near real-time monitoring of construction progress: integration of extended reality and kinect V2", SSRN available at: https://ssrn.com/ abstract $=3724058$.

Khajavi, S.H., Motlagh, N.H., Jaribion, A., Werner, L.C. and Holmström, J. (2019), "Digital twin: vision, benefits, boundaries, and creation for buildings", IEEE Access, Vol. 7, pp. 147406-147419, doi: 10.1109/ACCESS.2019.2946515.

Khalili, A. (2021), "An XML-based approach for geo-semantic data exchange from BIM to VR applications", Automation in Construction, Vol. 121, p. 103425, doi: 10.1016/j.autcon.2020. 103425.

Kim, S., Kim, S. and Lee, D.-E. (2020a), "3D point cloud and BIM-based reconstruction for evaluation of project by as-planned and as-built", Remote Sensing, Vol. 12 No. 9, p. 1457, doi: 10.3390/ rs12091457.

Kim, S., Kim, S. and Lee, D.-E. (2020b), "Sustainable application of hybrid point cloud and BIM method for tracking construction progress", Sustainability, Vol. 12 No. 10, p. 4106, doi: 10.3390/ su12104106.

Klempous, R., Kluwak, K., Idzikowski, R., Nowobilski, T. and Zamojski, T. (2017), "Possibility analysis of danger factors visualization in the construction environment based on Virtual Reality Model”, Cognitive Infocommunications (CogInfoCom), 2017 8th IEEE International Conference on, IEEE. doi: 10.1109/CogInfoCom.2017.8268271.

Kopsida, M. and Brilakis, I. (2020), "Real-time volume-to-plane comparison for mixed reality-based progress monitoring", Journal of Computing in Civil Engineering, Vol. 34 No. 4, 04020016, doi: 10.1061/(ASCE)CP.1943-5487.0000896.

Kropp, C., Koch, C. and König, M. (2018), "Interior construction state recognition with 4D BIM registered image sequences”, Automation in Construction, Vol. 86, pp. 11-32, doi: 10.1016/j. autcon.2017.10.027.

Kumar, V., Syan, A.S. and Kaur, K. (2020), "A structural equation modeling analysis of factors driving customer purchase intention towards solar water heater", Smart and Sustainable Built Environment. doi: 10.1108/SASBE-05-2020-0069.

Lin, J.J. and Golparvar-Fard, M. (2020), "Construction progress monitoring using cyber-physical systems", Cyber-Physical Systems in the Built Environment, Springer, pp. 63-87, doi: 10.1007/9783-030-41560-0_5.

Lin, J.J., Han, K.K. and Golparvar-Fard, M. (2015), "A framework for model-driven acquisition and analytics of visual data using UAVs for automated construction progress monitoring", Computing in Civil Engineering, pp. 156-164, doi: 10.1061/9780784479247.020.

Lin, J.J., Lee, J.Y. and Golparvar-Fard, M. (2019a), "Exploring the potential of image-based 3d geometry and appearance reasoning for automated construction progress monitoring", Computing in Civil Engineering 2019: Data, Sensing, and Analytics, American Society of Civil Engineers, Reston, VA, pp. 162-170, doi: 10.1061/9780784482438.021.

Lin, Z., Petzold, F. and Ma, Z. (2019b), "A real-time 4D augmented reality system for modular construction progress monitoring", ISARC. Proceedings of the International Symposium on Automation and Robotics in Construction, IAARC Publications, doi: 10.22260/ISARC2019/0100.

Liu, Z., Zhang, A. and Wang, W. (2020), "A framework for an indoor safety management system based on digital twin”, Sensors, Vol. 20 No. 20, p. 5771, doi: 10.3390/s20205771.

Lu, Q., Xie, X., Heaton, J., Parlikad, A.K. and Schooling, J. (2019), "From BIM towards digital twin: strategy and future development for smart asset management", International Workshop on Service Orientation in Holonic and Multi-Agent Manufacturing, Springer. doi: 10.1007/978-3-030-27477-1_30. 
SASBE 12,1

Lu, Q., Xie, X., Parlikad, A.K., Schooling, J.M. and Konstantinou, E. (2020), "Moving from building information models to digital twins for operation and maintenance", Proceedings of the Institution of Civil Engineers-Smart Infrastructure and Construction, pp. 1-11, doi: 10.1680/jsmic. 19.00011.

Machado, R.L. and Vilela, C. (2020), "Conceptual framework for integrating BIM and augmented reality in construction management", Journal of Civil Engineering and Management, Vol. 26 No. 1, pp. 83-94, doi: 10.3846/jcem.2020.11803.

Mathot, M., Hohrath, B., Rolvink, A. and Coenders, J. (2019), "Design modelling with next generation parametric system packhunt.io”, Design Modelling Symposium Berlin, Springer. doi: 10.1007/ 978-3-030-29829-6_22.

Meža, S., Mauko Pranjić, A., Vezočnik, R., Osmokrović, I. and Lenart, S. (2021), "Digital twins and road construction using secondary raw materials", Journal of Advanced Transportation. doi: 10.1155/ 2021/8833058.

Mo, Y., Zhao, D., Du, J., Liu, W. and Dhara, A. (2018), "Data-driven approach to scenario determination for VR-based construction safety training", Construction Research Congress. doi: 10.1061/ 9780784481288.012.

Nahangi, M. and Haas, C.T. (2015), "Skeleton-based discrepancy feedback for automated realignment of industrial assemblies", Automation in Construction, Vol. 61, pp. 147-161, doi: 10.1016/j.autcon. 2015.10.014.

Navon, R. and Sacks, R. (2007), "Assessing research issues in automated project performance control (APPC)", Automation in Construction, Vol. 16 No. 4, pp. 474-484, doi: 10.1016/j.autcon.2006. 08.001 .

Olorunfemi, A., Dai, F., Tang, L. and Yoon, Y. (2018), "Three-dimensional visual and collaborative environment for jobsite risk communication”, Construction Research Congress. doi: 10.1061/ 9780784481288.034.

Omar, T. and Nehdi, M.L. (2016), "Data acquisition technologies for construction progress tracking", Automation in Construction, Vol. 70, pp. 143-155, doi: 10.1016/j.autcon.2016.06.016.

Paes, D., Arantes, E. and Irizarry, J. (2017), "Immersive environment for improving the understanding of architectural 3D models: comparing user spatial perception between immersive and traditional virtual reality systems", Automation in Construction, Vol. 84, pp. 292-303, doi: 10. 1016/j.autcon.2017.09.016.

Pan, Y. and Zhang, L. (2021), "A BIM-data mining integrated digital twin framework for advanced project management”, Automation in Construction, Vol. 124, p. 103564, doi: 10.1016/j.autcon. 2021.103564 .

Perez-Perez, Y., Golparvar-Fard, M. and El-Rayes, K. (2021), "Segmentation of point clouds via joint semantic and geometric features for 3D modeling of the built environment", Automation in Construction, Vol. 125, p. 103584, doi: 10.1016/j.autcon.2021.103584.

Pica, D. and Abanda, F.H. (2021), "Emerging BIM-3d-laser scanning integration in construction practice", Collaboration and Integration in Construction, Engineering, Management and Technology, Springer, pp. 345-350, doi: 10.1007/978-3-030-48465-1_58.

Piroozfar, P., Judd, A., Boseley, S., Essa, A. and Farr, E.R. (2021), "Augmented reality for urban utility infrastructure: a UK perspective", Collaboration and Integration in Construction, Engineering, Management and Technology, Springer, pp. 535-541, doi: 10.1007/978-3-030-48465-1_88.

Potseluyko, L. and Rahimian, F. (2019), “A framework for improving business and technical operations within timber frame self-build housing sector by applying an integrated VR/AR and BIM approach", Construction and Management in Architecture, Engineering, Construction and Operations (AECO): 36th CIB W78 2019 Conference ICT in Design, ISBN 9781861354860.

Pučko, Z., Šuman, N. and Rebolj, D. (2018), "Automated continuous construction progress monitoring using multiple workplace real time 3D scans", Advanced Engineering Informatics, Vol. 38, pp. 27-40, doi: 10.1016/j.aei.2018.06.001. 
Puri, N. and Turkan, Y. (2020), "Bridge construction progress monitoring using lidar and 4D design models", Automation in Construction, Vol. 109, p. 102961, doi: 10.1016/j.autcon.2019.102961.

Rahimian, F.P., Seyedzadeh, S., Oliver, S., Rodriguez, S. and Dawood, N. (2020), "On-demand monitoring of construction projects through a game-like hybrid application of BIM and machine learning", Automation in Construction, Vol. 110, p. 103012, doi: 10.1016/j.autcon.2019. 103012.

Rashid, B. and Rehmani, M.H. (2016), "Applications of wireless sensor networks for urban areas: a survey", Journal of Network and Computer Applications, Vol. 60, pp. 192-219. doi: 10.1016/j.jnca. 2015.09.008.

Rasoolinejad, M., Dönmez, A.A. and Bažant, Z.P. (2020), "Fracture and size effect suppression by mesh reinforcement of concrete and justification of empirical shrinkage and temperature reinforcement in design codes", Journal of Engineering Mechanics, Vol. 146 No. 10, 04020120, doi: 10.1061/(ASCE)EM.1943-7889.0001850.

Rausch, C. and Haas, C. (2021), "Automated shape and pose updating of building information model elements from 3D point clouds", Automation in Construction, Vol. 124, p. 103561, doi: 10.1016/j. autcon.2021.103561.

Rausch, C., Sanchez, B., Esfahani, M.E. and Haas, C. (2020) "Computational algorithms for digital twin support in construction", Construction Research Congress 2020: Computer Applications, American Society of Civil Engineers, Reston, VA, doi: 10.1061/9780784482865.021.

Sacks, R., Brilakis, I., Pikas, E., Xie, H.S. and Girolami, M. (2020), "Construction with digital twin information systems”, Data-Centric Engineering, Vol. 1, doi: 10.1017/dce.2020.16.

Salehi, S.A. and Yitmen, İ. (2018), "Modeling and analysis of the impact of BIM-based field data capturing technologies on automated construction progress monitoring", International Journal of Civil Engineering, Vol. 16 No. 12, pp. 1669-1685, doi: 10.1007/s40999-018-0320-1.

Sanhudo, L., Ramos, N.M., Martins, J.P., Almeida, R.M., Barreira, E., Simões, M.L. and Cardoso, V. (2020), "A framework for in-situ geometric data acquisition using laser scanning for BIM modelling”, Journal of Building Engineering, Vol. 28, p. 101073, doi: 10.1016/j.jobe.2019.101073.

Shahi, A., Cardona, J.M., Haas, C.T., West, J.S. and Caldwell, G.L. (2012), "Activity-based Data Fusion for Automated Progress Tracking of Construction Projects", Construction Research Congress 2012: Construction Challenges in a Flat World, doi: 10.1061/9780784412329.085.

Shahi, A., Safa, M., Haas, C.T. and West, J.S. (2014), "Data fusion process management for automated construction progress estimation", Journal of Computing in Civil Engineering, Vol. 29 No. 6, 04014098, doi: 10.1061/(ASCE)CP.1943-5487.0000436.

Shi, Y., Du, J., Ragan, E., Choi, K. and Ma, S. (2018), "Social influence on construction safety behaviors: a multi-user virtual reality experiment", Construction Research Congress. doi: 10.1061/ 9780784481288.018.

Shirowzhan, S., Tan, W. and Sepasgozar, S.M. (2020), "Digital twin and cybergis for improving connectivity and measuring the impact of infrastructure construction planning in smart cities", Multidisciplinary Digital Publishing Institute. doi: 10.3390/ijgi9040240.

Sommer, M., Stjepandić, J., Stobrawa, S. and von Soden, M. (2019), "Automatic generation of digital twin based on scanning and object recognition", Advances in Transdisciplinary Engineering, Vol. 10, pp. 645-654, doi: 10.3233/ATDE190174.

Son, H., Bosché, F. and Kim, C. (2015), "As-built data acquisition and its use in production monitoring and automated layout of civil infrastructure: a survey", Advanced Engineering Informatics, Vol. 29 No. 2, pp. 172-183, doi: 10.1016/j.aei.2015.01.009.

Teizer, J. (2015), "Status quo and open challenges in vision-based sensing and tracking of temporary resources on infrastructure construction sites", Advanced Engineering Informatics, Vol. 29 No. 2, pp. 225-238, doi: 10.1016/j.aei.2015.03.006.
To develop a generic framework of a DT 
SASBE 12,1

Turkan, Y., Bosche, F., Haas, C.T. and Haas, R. (2012), "Automated progress tracking using 4D schedule and 3D sensing technologies", Automation in Construction, Vol. 22, pp. 414-421, doi: 10.1016/j.autcon.2011.10.003.

Turkan, Y., Bosché, F., Haas, C.T. and Haas, R. (2013), "Tracking secondary and temporary concrete construction objects using 3D imaging technologies", Computing in Civil Engineering, pp. 749-756, doi: 10.1061/9780784413029.094.

Tuttas, S., Braun, A., Borrmann, A. and Stilla, U. (2014), "Comparision of photogrammetric point clouds with bim building elements for construction progress monitoring. International archives of the photogrammetry", Remote Sensing and Spatial Information Sciences. doi: 10.5194/ isprsarchives-XL-3-341-2014.

Tuttas, S., Braun, A., Borrmann, A. and Stilla, U. (2016), "Evaluation of acquisition strategies for image-based construction site MonitoringInternational archives of the photogrammetry", Remote Sensing and Spatial Information Sciences, Vol. 41, doi: 10.5194/isprsarchives-XLI-B5733-2016.

Tuttas, S., Braun, A., Borrmann, A. and Stilla, U. (2017), "Acquisition and consecutive registration of photogrammetric point clouds for construction progress monitoring using a $4 \mathrm{D}$ BIM", $P F G$ Journal Of Photogrammetry, Remote Sensing and Geoinformation Science, Vol. 85 No. 1, pp. 3-15, doi: 10.1007/s41064-016-0002-z.

Waissi, G.R., Demir, M., Humble, J.E. and Lev, B. (2015), "Automation of strategy using IDEF0 - a proof of concept”, Operations Research Perspectives, Vol. 2, pp. 106-113, doi: 10.1016/j.orp.2015. 05.001.

Wen, J. and Gheisari, M. (2020), "Using virtual reality to facilitate communication in the AEC domain: a systematic review", Construction Innovation. doi: 10.1108/CI-11-2019-0122.

Wu, S., Hou, L. and Zhang, G.K. (2020), "Integrated application of BIM and eXtended reality technology: a review, classification and outlook", International Conference on Computing in Civil and Building Engineering, Springer, doi: 10.1007/978-3-030-51295-8_86.

Zhang, C. and Arditi, D. (2013), "Automated progress control using laser scanning technology", Automation in Construction, Vol. 36, pp. 108-116, doi: 10.1016/j.autcon.2013.08.012.

\section{Corresponding author}

Ibrahim Yitmen can be contacted at: ibrahim.yitmen@ju.se

For instructions on how to order reprints of this article, please visit our website:

www.emeraldgrouppublishing.com/licensing/reprints.htm

Or contact us for further details: permissions@emeraldinsight.com 